Northwestern University

From the SelectedWorks of C. Kirabo Jackson

February, 2012

Single-Sex Schools, Student Achievement, and Course Selection: Evidence from Rule-Based Student Assignments in Trinidad and Tobago

C. Kirabo Jackson, Northwestern University 


\section{Single-sex schools, student achievement, and course selection: Evidence from rule-based student assignments in Trinidad and Tobago}

\section{Kirabo Jackson}

Northwestern University, Institute for Policy Research, IL, United States

NBER, MA, United States

\section{A R T I C L E I N F O}

Article history:

Received 3 February 2011

Received in revised form 16 September 2011

Accepted 17 September 2011

Available online 1 October 2011

\section{Keywords:}

Single-sex schools

School quality

Student achievement

\begin{abstract}
A B S T R A C T
Existing studies on single-sex schooling suffer from biases because students who attend single-sex schools differ in unmeasured ways from those who do not. In Trinidad and Tobago, students are assigned to secondary schools based on an algorithm allowing one to address self-selection bias and estimate the causal effect of attending a single-sex school versus a similar coeducational school. While females with strong expressed preferences for single-sex schools have better 10th grade exam performance due to attending single-sex schools between grades 6 and10, most students perform no better at single-sex schools. Girls at single-sex-schools take fewer sciences courses.
\end{abstract}

(c) 2011 Elsevier B.V. All rights reserved.

\section{Introduction}

The merits of single-sex schooling have been fiercely debated in European, Latin American, and Caribbean nations where single-sex schools are prevalent. This debate has recently been ignited in the US with the passage of Title IX ${ }^{1}$ regulations making it easier for school districts to provide single-sex schools. If students have better academic outcomes in single-sex than coeducational (coed) schools, then overall educational attainment can be increased by merely shuffling students across schools to achieve sex-segregation. Also, if single-sex schooling reduces gendered course taking, it may lead to more efficient allocations of talent to courses and improved matching of workers to occupations. Under these scenarios, by making all schools single-sex, with no increased spending one can have a better educated population and cost-savings that can be put into productive sectors of the economy.

Using data from Trinidad and Tobago I aim to answer the following questions: (1) Does attending a single-sex secondary school from grades 6 through 10 affect 10th grade exam performance? (2) Do students with stronger preferences for single-sex schools experience larger benefits? (3) Do the effects vary by gender? (4) Do single-sex schools affect the course selection of girls and boys? This context is attractive for studying single-sex schools because about one quarter of public secondary schools are single-sex and institutional details allow one

\footnotetext{
${ }^{1}$ In 2006 Title IX regulations of the Education Amendments of 1972 were amended. Previously regulations permitted school districts to provide single-sex public schools only if they provided comparable single-sex public schools to both sexes. The new regulations only require providing equal coed schooling to students of the other sex (McLane et al., 2006).
}

to remove self-selection bias while comparing students at coed and single-sex schools that are similar along key dimensions.

One justification for single-sex education stems from the notion that boys and girls learn in different ways either due to different socialization $^{2}$ or biological differences ${ }^{3}$ so that single-sex schools allow teachers to tailor instruction to the particular needs of each sex. Another justification is that the presence of the opposite sex is distracting and leads to lower academic engagement (Coleman, 1961; Riordian, 1990; Trickett and Trickett, 1982). This is thought to be particularly important for girls because larger shares of boys within coed classrooms have been found to be associated with lower classroom achievement (Hoxby, 2000; Lavy and Schlosser, 2009). It is also argued that single-sex schooling increases the likelihood that boys/girls participate in traditionally female/male subjects either due to the salience of gender identities in coed settings (Jackson, 2009) or by deemphasizing differences in the timing of neurological development between boys and girls (James and Richards, 2003; Spielhofer et al., 2004). ${ }^{4}$

\footnotetext{
2 Pomerantz et al. (2002) and Beyer and Bowden (1997) find that girls are underconfident and Higgins (1991), Maccoby and Jacklin (1974), and Eagly (1978) find that girls care more about pleasing authority figures.

${ }^{3}$ Lenroot et al. (2007) find that girls complete about half of their brain development (as measured by adult mass) by age 11 compared to age 15 years for boys, and Killgore and Yurgelun-Todd (2004) find that in girls the language areas of the brain develop before the areas used for spatial relations and for geometry, while in boys, it's the other way around.

${ }^{4}$ Because girls develop the math portions of the brain later than boys, they are more likely to underperform in math and science at early ages and thus disengage from and avoid these subjects in a coed one-size-fits-all system. By the same logic, because boys develop the linguistic portions of the brain later than girls, boys are more likely to underperform in English and literature at early ages and disengage from and avoid these subjects in coed settings.
} 
Despite theory suggesting benefits of single-sex schools, and the potential importance for education policy, there is little conclusive empirical evidence on the effects of single-sex schooling on student outcomes. The empirical evidence, to date, is based on comparisons between children who chose to attend single-sex schools and those who do not. ${ }^{5}$ This evidence is unlikely to isolate the effect of single-sex schooling on student outcomes due to two important limitations. First, because students who decide to attend single-sex schools may differ from those who decide to attend coed schools in important unobserved ways, such comparisons may be subject to self-selection bias. Second, because single-sex schools often differ in important unobserved ways from coed schools (e.g. curriculum, academic calendar, selectivity) these comparisons may confound a single-sex school effect with other differences. I propose solutions to both of these limitations in this study.

To address self-selection bias, I exploit the fact that students in Trinidad and Tobago are assigned to secondary schools by the Ministry of Education based on their performance on a secondary school entrance exam and a list of school choices-so that attendance to single-sex schools is partially beyond their control. I use the algorithm that assigns students to schools to form rule-based instrumental variables that predict single-sex school attendance, but are not subject to selection. Under the assignment rules the likelihood of assignment to a single-sex school is a deterministic, non-linear, non-monotonic, non-smooth function of student choices and incoming test scores. Specifically, (a) conditional on two students having the same test score, differences in school assignments are due to their different choices, and (b) conditional on two students having the same choices, differences in school assignments are due to small differences in their test scores. This allows for both a Regression Discontinuity (RD) strategy and a Difference-inDifferences (DID) Instrumental Variables (IV) strategy that identifies the causal relationship off the interaction between student choices and test scores. I show that each of the two strategies independently yield similar results to each other and the preferred IV strategy that exploits all sources of exogenous variation. I also present a variety of tests indicating the instruments are exogenous.

To address concerns that single-sex schools differ from coed schools in other important ways, I focus the analysis to coed and single-sex public secondary schools that share the same curriculum, are subject to the same oversight, and follow the same regulations. As such, the single-sex and coed schools analyzed will not differ in most important dimensions that typically confound comparisons of schools in other contexts. While focusing on similar schools removes numerous sources of bias, there may still remain unobserved differences across schools that affect the interpretation of the findings. ${ }^{6}$ I document that single-sex schools are more selective than coed schools and they attract higher quality teachers. Based on this, I argue that the effects presented likely overstate the pure single-sex schooling effect.

A unique feature of these data is that I observe the number of singlesex schools a student lists in her school choices. Because this preference measure is strongly associated with single-sex school attendance, I can (a) determine if the treatment effect varies with preferences for singlesex schools, (b) determine if the treatment effect for those who typically

\footnotetext{
${ }^{5}$ Some US studies compare outcomes at single-sex catholic schools to outcomes in traditional public schools or coed catholic schools, (Lee and Bryk, 1986; Marsh, 1989; LePore and Warren, 1997) while studies outside the US compare outcomes at singlesex and coed public schools (Jimenez and Lockheed, 1989; (Harker, 2000; Malacova, 2007). The findings are decidedly mixed and none of these studies adjust for selection to schools (other than controlling for lagged achievement).

${ }^{6}$ Because school policies and inputs adjust endogenously in equilibrium to the student population, one could never expect a real-world situation where the only thing that differs between schools is whether they are single-sex. As such, a controlled randomized experiment in which the only thing that differed is that some schools were single-sex would not identify the policy relevant parameter (but would identify the short-run effect of making some schools single-sex). Thus, looking at actual schools, while imperfect, does allow one to say something about the policy relevant long-run effects.
}

apply to single-sex schools differ from that of the average student, and (c) speak to whether improved outcomes reflect better student-school matching or a technological improvement that benefits all students. The analysis is unique in this regard.

Under the assignment mechanism, students with higher entrance exam scores are more likely to be assigned to their more preferred schools. Because single-sex schools are often preferred, attending a single-sex school is also associated with attending a preferred school. While naive ordinary least squares yield large treatment effects, the instrumental variables results that account for selection show modest positive effects of gaining admission to a preferred single-sex school over a less preferred coed school. However, models that condition on gaining admission to a preferred school (of any type) yield treatment effects close to zero-indicating that the modest effects were due to gaining admission to a preferred school rather than attending a single-sex school per se. These average null effects mask considerable response heterogeneity. For students with weak preferences for single-sex schools (86\% of all students) the effects are close to zero. However, for students with strong preferences for single-sex schools ( $14 \%$ of all students), there are sizable benefits. Most of the estimated benefits to attending single-sex schools are driven by girls with strong preferences for single-sex schools. Contrary to common belief, girls took fewer science courses and more traditionally female subjects at single-sex schools.

This is the first study, to my knowledge, to identify a causal effect of single-sex schooling on student outcomes. The results suggest that previous studies may have suffered from student selection bias. The finding of heterogeneous treatment effects highlight that local treatment effects of schools for the typical applicant can be very misleading about effects for the average student. The results suggest that making single-sex schools available to those few students with strong preferences for single-sex schools may improve academic outcomes for these few students, but that expanding single-sex secondary schools to all students may have little effect on overall achievement, and may not be an effective tool for increasing female representation in math, science, and engineering fields.

The remainder of the paper is as follows: Section 2 describes the Trinidad and Tobago education system, the assignment mechanism, and the data. Section 3 describes the empirical framework, Section 4 presents the results, and Section 5 concludes.

\section{The Trinidad and Tobago education system and the data}

At the end of primary school (after grade 5) students take the Secondary Entrance Assessment (SEA) and are assigned to secondary schools based on scores on this exam and a list of four ranked school choices by the Ministry of Education. Secondary school begins in grade 6 and ends at grade 10 when students take the Caribbean Secondary Education Certification (CSEC) examinations. ${ }^{7}$ These exams are externally graded. Students seeking to continue their education typically take five or more subjects, and virtually all takers take the English language and mathematics exams. ${ }^{8}$

There are eight school districts. Private schools account for a small share of student enrollment and tend to serve those who "fall through the cracks" in the public system. ${ }^{9}$ There are two types of public secondary schools: Government schools and Government assisted (assisted) schools. All secondary schools provide instruction from 6th through 10th grade, and teach the same national curriculum.

\footnotetext{
There are 31 CSEC subjects covering a range of purely academic subjects such as Physics, Chemistry and Geography, and more work and vocationally related subjects such as Technical Drawing and Principles of Business and Office Procedures.

${ }^{8}$ The CSEC examinations are accepted as an entry qualification for higher education in Canada, the UK and the United States.

${ }^{9}$ Students who attend private secondary schools have test scores that are a third of a standard deviation lower than the average SEA taking student, and half a standard deviation lower than the average among those students who take the CSEC exams.
} 
Table 1

Comparison of inputs at single-sex and coed schools.

\begin{tabular}{|c|c|c|c|c|}
\hline Variable & Single-sex & Not single-sex & $\begin{array}{l}\text { Assisted and } \\
\text { not single-sex }\end{array}$ & $\begin{array}{l}\text { Not assisted and } \\
\text { not single-sex }\end{array}$ \\
\hline \multirow[t]{2}{*}{ Pupils/(\# faculty) } & 17.110 & 12.256 & 16.136 & 11.771 \\
\hline & $(3.475)$ & $(4.619)$ & $(7.105)$ & $(4.011)$ \\
\hline \multirow[t]{2}{*}{ Pupils/(\# academic teachers) } & 23.922 & 22.597 & 23.908 & 22.308 \\
\hline & (11.106) & $(16.531)$ & $(9.412)$ & $(17.231)$ \\
\hline \multirow[t]{2}{*}{ Teachers: \% BA } & 0.738 & 0.461 & 0.654 & 0.436 \\
\hline & $(0.176)$ & $(0.241)$ & $(0.235)$ & $(0.232)$ \\
\hline \multirow[t]{2}{*}{ Teachers: \% MA } & 0.060 & 0.024 & 0.035 & 0.022 \\
\hline & $(0.047)$ & $(0.034)$ & $(0.048)$ & $(0.032)$ \\
\hline \multirow[t]{2}{*}{ Academic teachers: \% BA } & 1.000 & 0.846 & 1.000 & 0.825 \\
\hline & - & $(0.130)$ & - & $(0.144)$ \\
\hline \multirow[t]{2}{*}{ Academic teachers: \% MA } & 0.080 & 0.040 & 0.059 & 0.038 \\
\hline & $(0.075)$ & $(0.038)$ & $(0.056)$ & $(0.036)$ \\
\hline \multirow[t]{2}{*}{ Assisted } & 0.912 & 0.111 & 1.000 & 0.000 \\
\hline & $(0.288)$ & $(0.316)$ & - & - \\
\hline \multirow{2}{*}{ Mean years of teaching experience } & 11.987 & 12.876 & 10.681 & 13.400 \\
\hline & $(4.492)$ & $(4.278)$ & $(3.672)$ & $(4.069)$ \\
\hline \multirow[t]{2}{*}{ School enrollment (2004) } & 664.588 & 638.879 & 524.546 & 653.171 \\
\hline & $(167.478)$ & $(263.568)$ & $(208.199)$ & $(267.226)$ \\
\hline \multirow[t]{2}{*}{ Grade 6 enrollment (2004) } & 108.471 & 114.111 & 96.182 & 116.352 \\
\hline & $(28.404)$ & $(49.243)$ & $(42.944)$ & $(49.737)$ \\
\hline \multirow[t]{2}{*}{ Mean score of assigned (2004) } & 1.212 & -0.183 & 0.736 & -0.282 \\
\hline & $(0.595)$ & $(0.903)$ & $(0.752)$ & $(0.862)$ \\
\hline \multirow[t]{2}{*}{ Standard dev. of score of assigned (2004) } & 0.446 & 0.709 & 0.504 & 0.753 \\
\hline & $(0.200)$ & $(0.196)$ & $(0.132)$ & $(0.178)$ \\
\hline Number of schools & 34 & 99 & 11 & 88 \\
\hline
\end{tabular}

Standard deviations in parentheses below sample means.

The key difference between Government and assisted schools is that Government schools are fully funded and operated by the Government while assisted schools are run by private bodies (usually a religious board) and at least half of their expenses are paid for by the Government. While assisted schools are often considered more elite, along all other dimensions Government and assisted schools are the same.

\subsection{Single-sex schools in Trinidad and Tobago}

There are 34 single-sex schools located primarily in larger districts across the country. In St Georges West 11 out of 32 secondary schools are single-sex, compared to 9 out of 31 for Victoria, 6 out of 18 for St Georges East, 6 out of 17 in Caroni, and 2 out of 14 for St. Patrick. There are no single-sex schools in the smaller districts of St. David, Tobago, and Mayaro which have 9, 8 , and 4 secondary schools, respectively. Trinidad is sufficiently small (about 37 by 50 miles) that, with the exception of Tobago which is a small island, a single-sex school is located within about 20 miles of any location. About 91\% of single-sexschools are assisted, and $74 \%$ of assisted schools are single-sex.

Table 1 summarizes teacher and peer inputs by school type for the 2004-5 academic year. Single-sex schools have a student to faculty ratio of 17.1 compared to 12.26 for coed schools. This is because coed schools hire more guidance officers, assistant teachers, and vocational teachers. I now focus on classroom teachers for academic courses. The student to teacher ratio is slightly higher at single-sex school (23.9 versus 22.59 at coed schools) and there are large differences in education level. Unlike in the US where all teachers must possess a college degree, some secondary school teachers only hold a high-school degree themselves. While all teachers at single-sex schools posses a BA degree only $85 \%$ do at coed schools. The average years of experience at single-sex schools is 11.98 years compared to 12.87 for coed schools. Given that the difference between possessing a high-school degree and a college degree is vast, the small differences in experience are likely trumped by the differences in education. In any case, teachers at single-sex schools are very similar to those at coed assisted schools-so that conditioning on school type may remove any teacher quality differences.
The largest observable input difference across schools is peer quality. The average student assigned to a single-sex school has incoming test scores that are 1.4 standard deviations higher than those of students assigned to coed schools. In fact, single-sex schools had 0.475 standard deviations higher incoming test scores than coed assisted schools. To show the distribution of peer achievement across schools, in Fig. $1 \mathrm{I}$ put the peer achievement across all schools in all years into ten equally spaced bins, and show the number of single-sex schools and coed schools that fall into each bin. The unit of observation is a school year. While there is overlap in the distribution of peer achievement between single-sex schools and coed schools, schools with the highest achieving peers are disproportionally single-sex schools. This, in conjunction with the differences in teacher education suggests that any estimated single-sex school effects will likely overstate the effects of single-sex schooling per se.

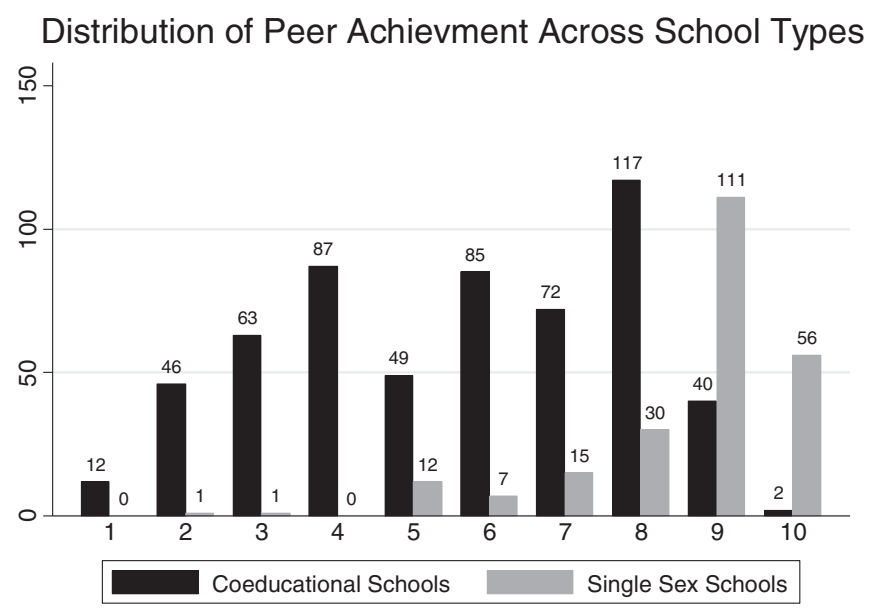

The data are placed in to 10 equally spaced bins. The unit of observation is a school year.

Fig. 1. Distribution of peer achievement across school types. 
Table 2

Summary statistics

\begin{tabular}{|c|c|c|c|c|c|c|c|c|}
\hline & \multicolumn{4}{|c|}{ All students } & \multicolumn{4}{|c|}{ All students with a simulated assignment } \\
\hline & $\begin{array}{l}\text { Attend } \\
\text { all-girls }\end{array}$ & $\begin{array}{l}\text { Attend mixed: } \\
\text { female }\end{array}$ & $\begin{array}{l}\text { Attend } \\
\text { all-boys }\end{array}$ & $\begin{array}{l}\text { Attend mixed: } \\
\text { male }\end{array}$ & $\begin{array}{l}\text { Assigned } \\
\text { all-girls }\end{array}$ & $\begin{array}{l}\text { Assigned mixed: } \\
\text { female }\end{array}$ & $\begin{array}{l}\text { Assigned } \\
\text { all-boys }\end{array}$ & $\begin{array}{l}\text { Assigned mixed: } \\
\text { male }\end{array}$ \\
\hline Normalized SEA score & $\begin{array}{l}0.836 \\
(0.868)\end{array}$ & $\begin{array}{l}-0.074 \\
(0.882)\end{array}$ & $\begin{array}{l}0.792 \\
(0.882)\end{array}$ & $\begin{array}{l}-0.343 \\
(0.938)\end{array}$ & $\begin{array}{l}1.498 \\
(0.457)\end{array}$ & $\begin{array}{l}-0.041 \\
(0.862)\end{array}$ & $\begin{array}{l}1.315 \\
(0.569)\end{array}$ & $\begin{array}{l}-0.316 \\
(0.922)\end{array}$ \\
\hline Female & $\begin{array}{l}1.000 \\
(0.0)\end{array}$ & $\begin{array}{l}1.000 \\
(0.0)\end{array}$ & $\begin{array}{l}0.000 \\
(0.0)\end{array}$ & $\begin{array}{l}0.000 \\
(0.0)\end{array}$ & $\begin{array}{l}1.000 \\
(0.0)\end{array}$ & $\begin{array}{l}1.000 \\
(0.0)\end{array}$ & $\begin{array}{l}0.000 \\
(0.0)\end{array}$ & $\begin{array}{l}0.000 \\
(0.0)\end{array}$ \\
\hline Take CSEC exams & $\begin{array}{l}1.000 \\
(0.0)\end{array}$ & $\begin{array}{l}0.564 \\
(0.496)\end{array}$ & $\begin{array}{l}1.000 \\
(0.0)\end{array}$ & $\begin{array}{l}0.459 \\
(0.498)\end{array}$ & $\begin{array}{l}0.903 \\
(0.296)\end{array}$ & $\begin{array}{l}0.630 \\
(0.483)\end{array}$ & $\begin{array}{l}0.873 \\
(0.333)\end{array}$ & $\begin{array}{l}0.519 \\
(0.5)\end{array}$ \\
\hline Exams taken & $\begin{array}{l}6.582 \\
(1.607)\end{array}$ & $\begin{array}{l}3.339 \\
(3.15)\end{array}$ & $\begin{array}{l}6.288 \\
(1.77)\end{array}$ & $\begin{array}{l}2.464 \\
(2.919)\end{array}$ & $\begin{array}{l}6.641 \\
(2.395)\end{array}$ & $\begin{array}{l}3.736 \\
(3.119)\end{array}$ & $\begin{array}{l}6.153 \\
(2.633)\end{array}$ & $\begin{array}{l}2.795 \\
(2.969)\end{array}$ \\
\hline Exams passed & $\begin{array}{l}5.121 \\
(2.707)\end{array}$ & $\begin{array}{l}1.809 \\
(2.462)\end{array}$ & $\begin{array}{l}4.290 \\
(2.822)\end{array}$ & $\begin{array}{l}1.053 \\
(1.985)\end{array}$ & $\begin{array}{l}6.178 \\
(2.58)\end{array}$ & $\begin{array}{l}2.094 \\
(2.569)\end{array}$ & $\begin{array}{l}5.002 \\
(2.874)\end{array}$ & $\begin{array}{l}1.228 \\
(2.1)\end{array}$ \\
\hline Pass CSEC English & $\begin{array}{l}0.782 \\
(0.413)\end{array}$ & $\begin{array}{l}0.311 \\
(0.463)\end{array}$ & $\begin{array}{l}0.669 \\
(0.471)\end{array}$ & $\begin{array}{l}0.163 \\
(0.37)\end{array}$ & $\begin{array}{l}0.860 \\
(0.347)\end{array}$ & $\begin{array}{l}0.360 \\
(0.48)\end{array}$ & $\begin{array}{l}0.756 \\
(0.429)\end{array}$ & $\begin{array}{l}0.194 \\
(0.395)\end{array}$ \\
\hline Pass CSEC Math & $\begin{array}{l}0.620 \\
(0.485)\end{array}$ & $\begin{array}{l}0.184 \\
(0.388)\end{array}$ & $\begin{array}{l}0.597 \\
(0.491)\end{array}$ & $\begin{array}{l}0.130 \\
(0.336)\end{array}$ & $\begin{array}{l}0.825 \\
(0.38)\end{array}$ & $\begin{array}{l}0.214 \\
(0.41)\end{array}$ & $\begin{array}{l}0.721 \\
(0.448)\end{array}$ & $\begin{array}{l}0.152 \\
(0.359)\end{array}$ \\
\hline Certificate & $\begin{array}{l}0.568 \\
(0.495)\end{array}$ & $\begin{array}{l}0.141 \\
(0.348)\end{array}$ & $\begin{array}{l}0.481 \\
(0.5)\end{array}$ & $\begin{array}{l}0.078 \\
(0.268)\end{array}$ & $\begin{array}{l}0.796 \\
(0.403)\end{array}$ & $\begin{array}{l}0.166 \\
(0.372)\end{array}$ & $\begin{array}{l}0.633 \\
(0.482)\end{array}$ & $\begin{array}{l}0.092 \\
(0.288)\end{array}$ \\
\hline Female subjects taken & $\begin{array}{l}3.099 \\
(1.365)\end{array}$ & $\begin{array}{l}1.362 \\
(1.576)\end{array}$ & $\begin{array}{l}2.171 \\
(1.452)\end{array}$ & $\begin{array}{l}0.657 \\
(1.139)\end{array}$ & $\begin{array}{l}3.004 \\
(1.566)\end{array}$ & $\begin{array}{l}1.590 \\
(1.642)\end{array}$ & $\begin{array}{l}2.300 \\
(1.471)\end{array}$ & $\begin{array}{l}0.765 \\
(1.217)\end{array}$ \\
\hline Female subjects passed & $\begin{array}{l}2.473 \\
(1.609)\end{array}$ & $\begin{array}{l}0.810 \\
(1.292)\end{array}$ & $\begin{array}{l}1.566 \\
(1.426)\end{array}$ & $\begin{array}{l}0.332 \\
(0.814)\end{array}$ & $\begin{array}{l}2.810 \\
(1.618)\end{array}$ & $\begin{array}{l}0.977 \\
(1.396)\end{array}$ & $\begin{array}{l}1.855 \\
(1.451)\end{array}$ & $\begin{array}{l}0.396 \\
(0.886)\end{array}$ \\
\hline Sciences taken & $\begin{array}{l}1.097 \\
(1.147)\end{array}$ & $\begin{array}{l}0.419 \\
(0.836)\end{array}$ & $\begin{array}{l}1.283 \\
(1.247)\end{array}$ & $\begin{array}{l}0.349 \\
(0.775)\end{array}$ & $\begin{array}{l}1.485 \\
(1.229)\end{array}$ & $\begin{array}{l}0.456 \\
(0.852)\end{array}$ & $\begin{array}{l}1.487 \\
(1.343)\end{array}$ & $\begin{array}{l}0.399 \\
(0.813)\end{array}$ \\
\hline Sciences passed & $\begin{array}{l}0.929 \\
(1.13)\end{array}$ & $\begin{array}{l}0.229 \\
(0.618)\end{array}$ & $\begin{array}{l}0.949 \\
(1.222)\end{array}$ & $\begin{array}{l}0.173 \\
(0.564)\end{array}$ & $\begin{array}{l}1.393 \\
(1.232)\end{array}$ & $\begin{array}{l}0.260 \\
(0.647)\end{array}$ & $\begin{array}{l}1.245 \\
(1.335)\end{array}$ & $\begin{array}{l}0.199 \\
(0.598)\end{array}$ \\
\hline Hard sciences taken & $\begin{array}{l}0.443 \\
(0.762)\end{array}$ & $\begin{array}{l}0.145 \\
(0.477)\end{array}$ & $\begin{array}{l}0.671 \\
(0.873)\end{array}$ & $\begin{array}{l}0.153 \\
(0.476)\end{array}$ & $\begin{array}{l}0.710 \\
(0.876)\end{array}$ & $\begin{array}{l}0.150 \\
(0.482)\end{array}$ & $\begin{array}{l}0.838 \\
(0.929)\end{array}$ & $\begin{array}{l}0.174 \\
(0.503)\end{array}$ \\
\hline Hard sciences passed & $\begin{array}{l}0.381 \\
(0.727)\end{array}$ & $\begin{array}{l}0.066 \\
(0.326)\end{array}$ & $\begin{array}{l}0.495 \\
(0.813)\end{array}$ & $\begin{array}{l}0.061 \\
(0.317)\end{array}$ & $\begin{array}{l}0.664 \\
(0.867)\end{array}$ & $\begin{array}{l}0.071 \\
(0.337)\end{array}$ & $\begin{array}{l}0.705 \\
(0.899)\end{array}$ & $\begin{array}{l}0.070 \\
(0.338)\end{array}$ \\
\hline Observations & 24648 & 87625 & 19689 & 86642 & 12162 & 67903 & 11961 & 60231 \\
\hline
\end{tabular}

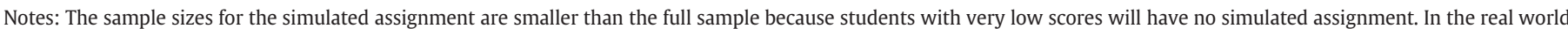
such students are assigned to schools based on arability and proximity.

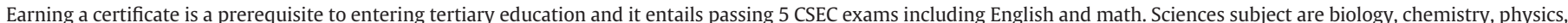

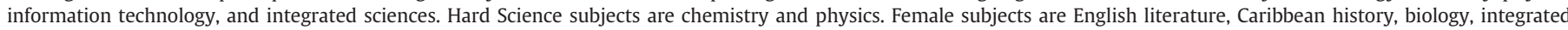

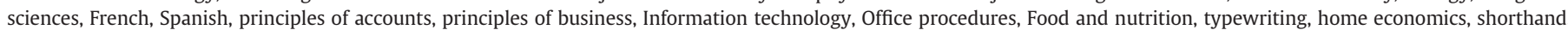
and clothing and textiles.

\subsection{Data and summary statistics}

The data used come from the official SEA test score data (5th grade) for the 1995 through 2002 cohorts and the official 2000 through 2007 CSEC test score data (10th grade). The SEA data contain each of the nation's student's SEA test scores, their list of preferred secondary schools, their gender, age, religion, primary school district, and the secondary school to which they were assigned by the Ministry of Education. ${ }^{10}$ I link the SEA data with the CSEC data both four and five years later. Roughly two-thirds of SEA takers were linked to CSEC exam data. ${ }^{11}$ The CSEC data contain each student's grades on each CSEC exam and secondary school they attended. The school attended is the school at which the student took the CSEC. For those who do not take the CSEC, I use the official school assignment from the Ministry of Education. There are 123 public secondary schools and several small test taking centers and private schools. Of these schools, 34 are single-sex schools which are split almost evenly between all-boys and all-girls schools. Among students linked to CSEC data, under 7\% attended a private institution, were home schooled, or were unaffiliated with any public education institution. I determine whether a student took the CSEC exams, compute the number of examinations taken and passed, and determine the courses taken. Taking a subject is defined as taking a CSEC exam in the subject. The resulting dataset contains 219,849 students across seven cohorts and 123 schools.

\footnotetext{
10 The SEA exam is comprised of math, English, science, social studies, and an essay.

11 Students were matched based on name, gender and date of birth. The match rate was just over 70\%, similar to the national dropout rate. Students with missing CSEC data are included in all regressions and coded as having zero passes.
}

Table 2 summarizes the data broken up by single-sex school attendance, assignment, and gender. Girls and boys assigned to all-girls and all-boys schools have test scores that are 1.45 and 0.99 standard deviations higher than those of girls and boys assigned to coed schools, respectively. Similarly, the average outcomes are much better at single-sex schools. About $90.3 \%$ of girls assigned to all-girls schools remain in secondary school to take the CSEC exams five years after entering secondary school compared to only $63 \%$ at coed schools. While $87.3 \%$ of boys assigned to all-boys schools remain in secondary school to take the CSEC exams, only $51.9 \%$ do at coed schools. Girls and boys assigned to single-sex schools pass 6.18 and 5 CSEC exams respectively, compared to only 2.09 and 1.22 at coed schools for girls and boys, respectively. An important academic outcome is earning a certificate (passing 5 exams including math and English) because it is the prerequisite to tertiary education. Girls and boys assigned to single-sex schools have a likelihood of earning a certificate of 0.796 and 0.63 compared to 0.16 and 0.09 for girls and boys assigned to coed schools, respectively.

I classify courses into Sciences (biology, chemistry, physics, information technology, and integrated sciences) and Female dominated subjects (defined as any subject where more than two-thirds of all participants were female in 1999). ${ }^{12}$ Students assigned to single-sex schools take more of all subject types than those assigned to coed schools. This is also true for those who take the CSEC exams-so

\footnotetext{
12 These subjects are literature, history, biology, integrated sciences, French, Spanish, principles of accounts, business, Information technology, office procedures, food and nutrition, typewriting, home economics, shorthand, clothing and textiles.
} 
that this is not driven by higher CSEC exam taking at single-sex schools.

A key variable in this analysis is student choices. Students' school choices are based largely on their own perceived ability, geography, and religion. Higher achieving students tend to have higher achievement schools in their list, students often list schools with the same religious affiliation as their own, and list schools that are geographically close to their homes. Also, students tend to put schools with higherachieving peers higher up on their preference ranking. On average, the difference between the mean incoming SEA scores at a student's top choice school and their second, third, and fourth choice school is $0.277,0.531$, and 0.82 standard deviations, respectively. This is shown in Appendix Figure A1. Roughly $58 \%$ of students have a singlesex school as one of their four secondary school choices and students tend to put single-sex schools higher up in their list. Specifically, roughly half of students list a single-sex school as their top choice school (47\% for boys and $52 \%$ for girls), while about one third list a single-sex school as their second choice (29\% for boys and $33 \%$ for girls), one fifth list a single-sex school as their third choice (18\% for boys and $21 \%$ for girls), and about one tenth list a single-sex school as their fourth choice $(9 \%$ for boys and $10 \%$ for girls).

\section{Econometric framework}

\subsection{Identification strategy}

In this section I describe how I aim to identify the effect of attending a single-sex school. To do this, I compare the outcomes of similar students who attend different schools. For the baseline specification, I model the outcome of student $i$ at school $j$ with the following equation.

$Y_{i j}=f\left(S E A_{i}\right)+\operatorname{single}_{i j} \sigma+X_{i} \delta+\sum_{c=1} I_{i c} \cdot \theta_{c}+\varepsilon_{i j}$

In (1), single $e_{i j}$ is an indicator variable equal to 1 if the student attends a single-sex school and equal to 0 otherwise, $S E A_{i}$ is a matrix of incoming test scores, $X_{i}$ is student gender, $I_{i c}$ is an indicator variable denoting the school choice list of student $i$ (an indicator variable identifying each unique list of four choices), ${ }^{13}$ and $\varepsilon_{i j}$ is the idiosyncratic error term. The parameter $\sigma$ is the effect of attending a single-sex school. While including individual SEA scores and school choices should remove a large amount of self-selection bias, OLS estimates of $\sigma$ may suffer from bias if students can select to schools based on unobserved dimensions. In the following sections I detail how students are assigned to schools, explain why there may be selection to single-sex schools, and detail how I use the assignment rules to remove selection bias and identify the causal effect of attending a single-sex school relative to a coed school.

\subsection{Student assignment rules}

Students in Trinidad and Tobago compete for a limited number of places at premium schools. After 5th grade, students take the Secondary Entrance Assessment (SEA) examinations. Each student lists four ordered secondary school choices. These choices and their SEA score are used by the Ministry of Education to assign them to schools using an algorithm. School slots are assigned in successive rounds such that the most highly subscribed/ranked school fills its spots in the first round, then the next highly subscribed school fills its slots in the second round, and so on until all school slots are filled. This is done as follows: (1) The number of school slots at each school $n_{j}$ is predetermined based

\footnotetext{
13 Each choice group is defined by a distinct ordering of schools. Students who list schools A, B, C, D in that order form a group, while students who list schools B, A, C, $D$ form a different group because even though they have the same schools, the ordering is different. There are 22,649 choice groups with more than one student. Among these groups, the average has 63 students.
}

on capacity constraints. (2) Students are tentatively placed in the applicant pools for their first choice schools and are ranked in descending order by SEA score within each application pool. (3) The school at which the $n_{j}^{\text {th }}$ ranked applicant has the highest SEA score is determined to be the most highly subscribed/ranked school, this score becomes the cut-off score for this school, and the top $n_{j 1}$ students in the applicant pool for top-ranked school $j_{1}$ are admitted to school $j_{1}$. (4) The topranked school's slots and the admitted students are removed from the process, and the second choice becomes the new "first choice" for students who had the top-ranked school as their first choice but did not gain admission. (5) This process is repeated in round two to assign students to the second highest ranked school $j_{2}$ and determine the cut-off score for the second ranked school. This is repeated in subsequent rounds until all slots are filled.

This process applies to over 95\% of students. However, assisted schools (which account for $16 \%$ of school slots) can admit $20 \%$ of their incoming class at the principal's discretion. As such, the rule is used to assign $80 \%$ of the students at these schools, while the remaining $20 \%$ can be hand-picked by the principal before the next-highest ranked school fills any of its slots. For example, suppose the highest ranked school has 100 slots and is an assisted school. The top 80 applicants to that school will be assigned to that school while the principal can hand-pick 20 other students at their discretion. The remaining 20 students would be chosen based on family alumni connections, being relatives of teachers, or religious affiliation. These hand-picked students may list the school as their top choice, but this need not be the case. Students receive one assignment and are never made aware of other schools they would have been assigned to had they not been hand-picked. Only after all the spots (the assigned $80 \%$ and the hand-picked 20\%) at the highest ranked school have been filled will the process be repeated for the remaining schools. As such, the school assignments are based partly on the described deterministic function of student test scores and student choice and partly on the endogenous selection of students by school principals.

\subsection{Simulating the student assignments using the rules}

Unfortunately, the actual cut-off scores for each school are not released to the public and those students who were hand-picked cannot be identified in the data. However, because the rules are known and I have the same information that the Ministry of Education uses to assign students, using only the deterministic portion of algorithm described above I can determine where the cut-offs would have been (and therefore the school's students would have been assigned to) if assisted schools could not hand-pick students. The only difference between how students are actually assigned and the simulated "tweaked" rule-based assignment is that at step (3) the "tweaked" rule does not allow any students to be hand-picked while, in fact, some students are hand-picked by principals only at assisted schools.

To show the validity of the simulation, I estimate the likelihood of assignment to a preferred school as a function of one's score relative to the simulated cut-off for that school. To do this I combine several cut-offs into one. Specifically, for each school I find all students who list that school as the top choice, re-center those students' scores around the cut-off for that school, and create a sample of applicants for each school. To mimic the sequential nature of the algorithm, I remove students assigned to their top choice schools, replace students' first choice with their second choice, and repeat this process with the second, third, and fourth choices. The applicant samples for all schools are then stacked so that every student has one observation for each school for which they were an applicant. Because scores are re-centered, scoring above zero means scoring above the cut-off for a preferred school.

I present the relationship between being assigned to one's preferred school as a function of one's incoming test score relative to the simulated cut-off for the preferred school in Fig. 2. On the left I use all the observations, while on the right I exclude students whose assignment is not 

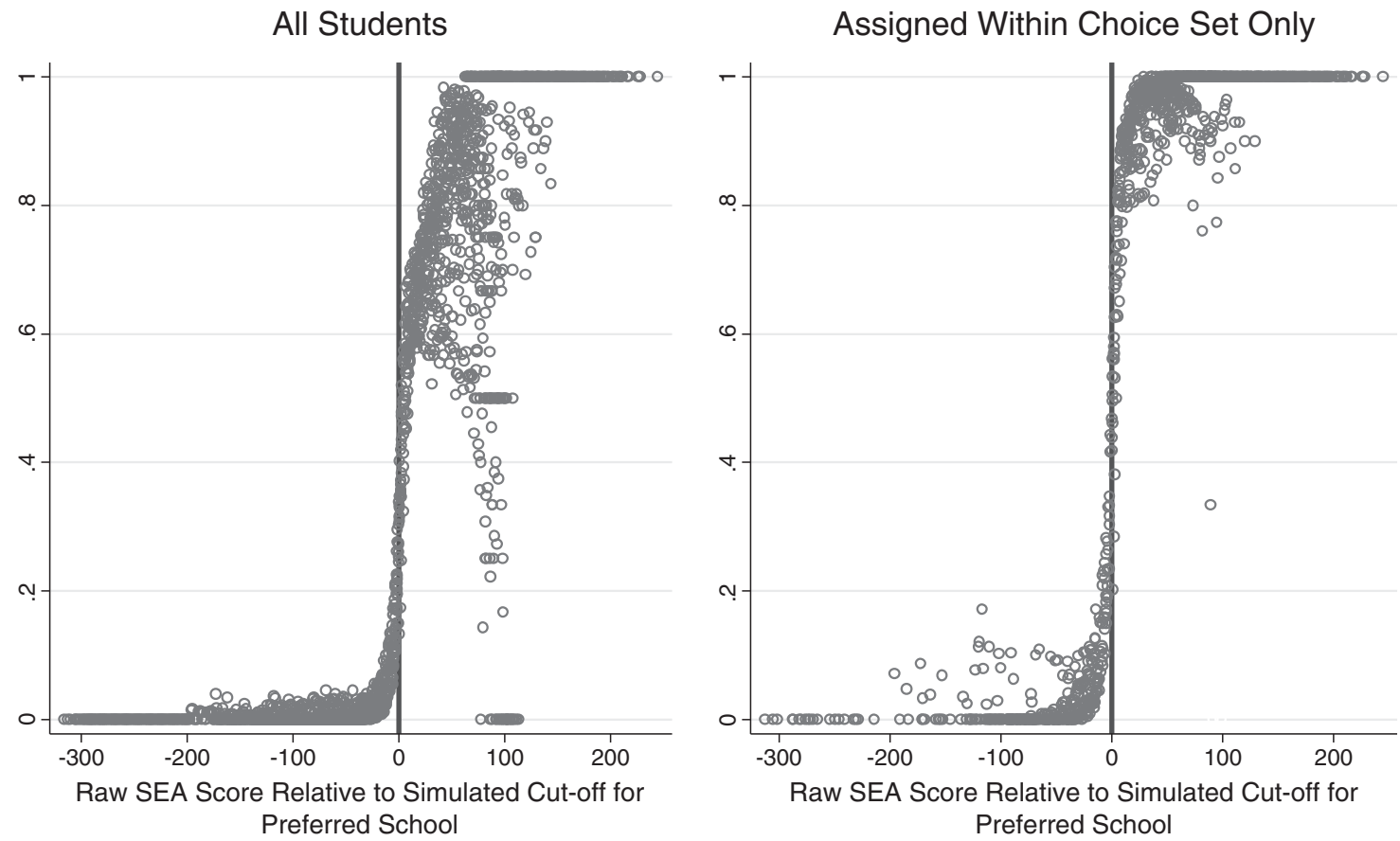

Fig. 2. Likelihood of being assigned to a preferred school.

one of their four choices (for whom scoring above a cut-off could not result in any treatment differential). If there were no selection or handpicking of students by principals, the figure would be a step function. However, there is a rapid increase in the likelihood of being assigned to a preferred school as one's score goes from below to above the simulated cut-off-indicating that the assignments operate as described so that there are meaningful differences in schooling environments associated with scoring above versus below a simulated cut-off that are not due to selection. The fact that the assignment rules create exogenous cut-offs that are well approximated by the simulated cut-offs plays a central role in my identification strategy.

\subsection{Rule-based instrument}

To remove selection bias from the actual school attended, I use the school assignments that would prevail if assisted schools could not select students. For each school student pair, I define $R_{u l} e_{i j}$ that is equal to 1 if student $i$ would have been assigned to school $j$ had there been no student selection or principal hand-picking and 0 otherwise. That is, Rule $_{i j}$ is equal to 1 if student $i$ is assigned to school $j$ based on the simulations described above and 0 otherwise. Rule $_{i j}$ is the deterministic portion of the student assignment algorithm. Because this deterministic portion of the assignment mechanism is used to assign most students to schools, the simulated assignments are correlated with the school's students attend. ${ }^{14}$ However, since the deterministic portion of the assignment mechanism cannot be manipulated by students or school principals, the simulated assignments should be uncorrelated with unobserved student characteristics such as motivation and ability, conditional on student test scores and school choices. I propose instrumental variables strategies based on these simulated assignments.

\subsubsection{Sources of exogenous variation and the econometric models}

Conditional on incoming test scores and choices, Rule is $_{\text {captures }}$ two plausibly exogenous sources of variation in single-sex school

\footnotetext{
${ }^{14}$ About $60 \%$ of students take the CSEC exams at the school to which they were initially assigned.
}

assignment and attendance. I discuss these two distinct sources of exogenous variation, and describe instrumental variables estimation strategies that exploit them.

Exogenous variation due to test score cut-offs. According to the simulated assignment mechanism the only reason two students with the same set of school choices are assigned to different schools would be due to differences in their tests scores. Specifically, conditional on school choices, the assignment rule creates test score cut-offs above which students are assigned to one school and below which they are assigned to another. As such, one source of exogenous variation comes from comparing the outcomes of students assigned to different schools (one of which is a single-sex school) who score just above and just below a cut-off. The logic is similar to a regression discontinuity design. Among students who chose a single-sex school, the likelihood of being assigned to (and attending) a single-sex school increases in a sudden and discontinuous manner as one's score goes from below to above the cut-off for that single-sex school (see Fig. 2). If the location of the cut-offs are orthogonal to student characteristics, and the effect of test scores on outcomes are smooth through the cut-offs, one can attribute any sudden jumps in the outcomes as one's score goes from below to above the cut-offs to the sudden increased likelihood of attending one's preferred single-sex school.

To isolate the discontinuity based variation, I implement something similar to a fuzzy RD design. Using the stacked dataset described in Section 3.3, I create a subsample of cut-offs for preferred single-sex schools. Using this subsample, Fig. 3 presents visual evidence of a rapid increase in the likelihood of attending a preferred single-sex school through the simulated cut-off for a preferred single-sex school. The figure also shows that the increase in likelihood is somewhat smooth-suggesting that results using variation through the cut-offs alone may be sensitive to how one controls for smoothness through the cut-offs. Fig. 3 also shows suggestive visual evidence of a discontinuity through the main outcomes (number of exams passed and earning a certificate). Due to the noisiness of this procedure, this is not the preferred source of variation. However, it is worthwhile to see what a discontinuity-type design might yield, and to see if the results are similar to those obtained using other sources of variation. 


\section{Change in Treatment and Outcomes Through Simulated Cut-offs}

All Cut-offs
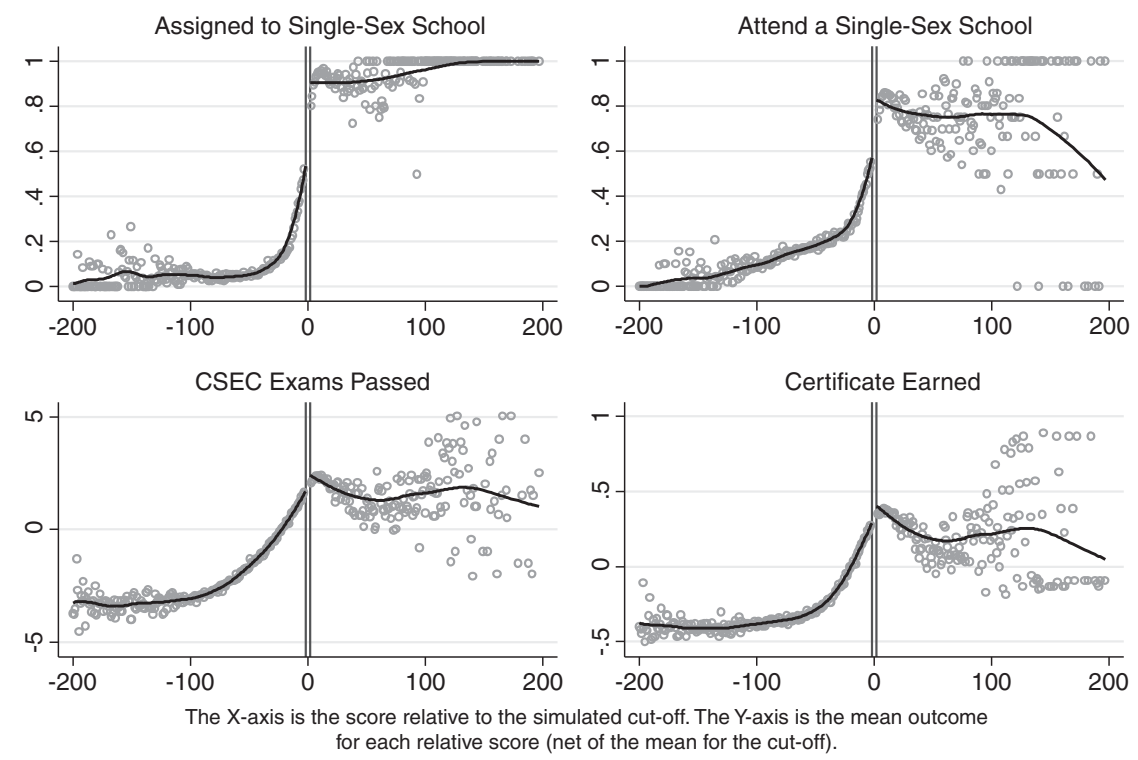

Fig. 3. Aggregate cut-offs.

Using the stacked dataset, I use scoring above the simulated cutoff for a preferred single-sex school as an instrument for attending a preferred single-sex school. Specifically, I estimate (2) by 2SLS.

$$
\begin{aligned}
\text { single }_{i j} & =f_{1}\left(S E A_{i}\right)+\text { Above }_{i j} \cdot \varphi_{1}+v_{j 1}+\varepsilon_{i j 1} \\
Y_{i j} & =f_{2}\left(S E A_{i}\right)+\text { single }_{i j} \sigma_{j, 2}+v_{j 2}+\varepsilon_{i j 2} .
\end{aligned}
$$

All variables are defined as before, $A_{b o v e}$ is an indicator variable equal to 1 if student $i$ has a SEA score above the simulated cut-off for single-sex school $j$ and 0 otherwise, and $\nu_{j}$ is a fixed effect for each cut-off (preferred school) to account for the fact that students in the admission pool for the top single-sex school may have different characteristics from those in the applicant pool for a less selective single-sex school. I present results using a second, third, fourth, fifth order polynomial in the SEA score. The first stage F-statistics are all above 100. Standard errors are clustered at the cut-off level.

Exogenous variation due to the interaction between school choices and test scores. The second source of variation comes from the fact that different schools have different cut-offs so that students with the same test scores but different choices are assigned to different schools. This variation is best illustrated with a simple example. Consider a world with two single-sex schools 1 and 2 and one coed school 3 . There are two choice groups; choice group 1 who list school 1 as their top choice and school 3 as their second; and choice group 2 who list school 2 as their top choice and school 3 as their second choice. Applicants to school 1 who score above 82 on the SEA are granted admission, while school 2 has a higher cut-off such that applicants to school 2 who score above 92 on the SEA are granted admission. One can put all students into one of three test score groups: group A with scores of 82 and below; group B with scores between 83 and 92; and group C with scores of 93 and above. This is illustrated in Fig. 4.

Students in test score group A (with scores below the cut-offs for both single-sex schools) are never admitted to a single-sex school whether they are in choice group 1 or choice group 2 . Similarly, students in test score group C (with scores above the cut-offs for both single-sex schools) are all admitted to a single-sex school whether they are in choice group 1 or choice group 2. However, those in test score group B (with scores above the cut-off for school 1 but below the cutoff for school 2) who are in choice group 1 are admitted to a single-sex school while those in choice group 2 are not admitted to a single-sex school. As such, if the choice group effects is additively

School 1 is top choice

School 2 is top choice
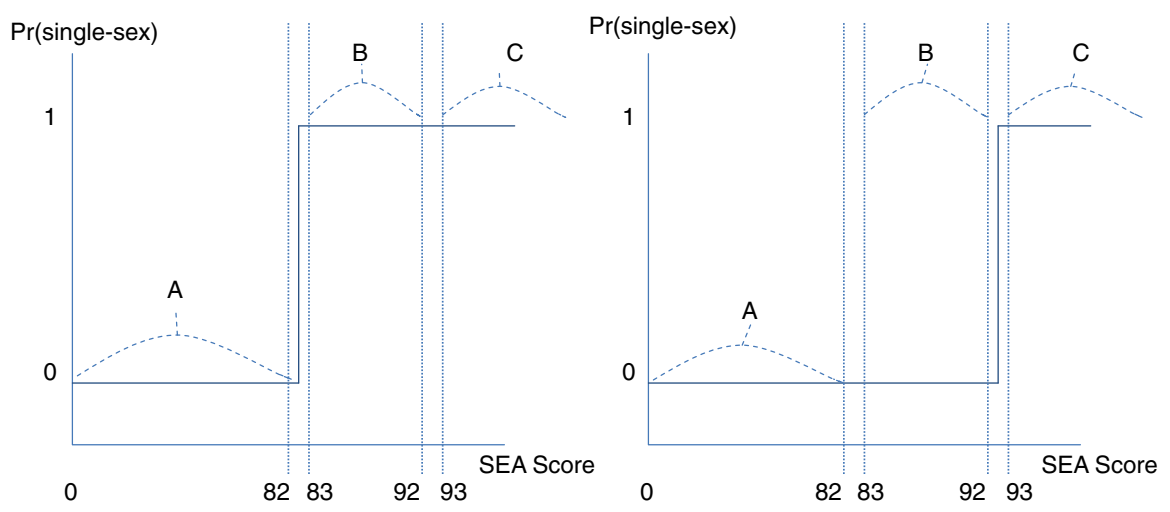

Fig. 4. A graphical illustration of the difference in difference variation. 
separable from that of test scores, one can use a difference in difference approach to identify the effect of attending a single-sex school.

Specifically, because the difference in choices do not lead to a difference in single-sex school attendance within test score groups A and C, the difference in outcomes between choice groups 1 and 2 within test score groups $\mathrm{A}$ and $\mathrm{C}$ cannot be due to differences in test scores or differences in single-sex school attendance and must therefore be due to differences in choices. However, because the difference in choices lead to a differences in single-sex school attendance within test score range $B$, the difference in outcomes between choice groups 1 and 2 within test score group B reflects both differences in single-sex school attendance and differences in choices. As long as the effect of choices is the same across all test score levels then the difference in outcomes between choice groups 1 and 2 within test score group B (single-sex effect + choice group effect), minus the difference in outcomes between choice groups 1 and 2 within test score groups A or C (choice group effect), reflects the effect of attending a single-sex school.

To capture only the difference in difference (DID) variation obtained by looking at the difference in outcomes for students with exactly the same test scores but who attend different schools because of differences in the locations of the cut-offs of their school choices, I use a DID-2SLS strategy estimating the effect of attending a preferred single-sex school after controlling for a full set of choice indicator variables, and a full set of test score indicator variables (i.e. an indicator variable for each distinct total SEA score for each test year, removing all variation due to sudden changes in outcomes through cut-offs).

single $_{i j}=\sum_{t=1} \theta_{1 t} \cdot I_{\text {SEA }_{i}=t}+\gamma_{1}\left(\overline{\text { single }} \mid\right.$ Rule $\left._{i j}\right)+X_{i} \delta_{1}+\sum_{c=1} I_{i, c} \cdot \theta_{c 1}+\varepsilon_{i, j, 1}$
$Y_{i j}=\sum_{\mathrm{t}=1} \theta_{2 t} \cdot I_{S E A_{i}=t}+\operatorname{single}_{i j} \sigma+X_{i} \delta_{2}+\sum_{c=1} I_{i, c} \cdot \theta_{c 2}+\varepsilon_{i j 2}$

In (3), single $e_{i j}$ is an indicator variable denoting whether a student attends a single-sex school, $X_{i}$ is student sex, $I_{i, c}$ is an indicator variable equal to 1 if a student's rank ordering is choice group $c$ and equal to zero otherwise, ${ }^{15} I_{\text {SEAi-t } t}$ is an indicator variable equal to 1 if the students SEA score is equal to $t$, and ( $\overline{\text { single }} \mid$ Rule $_{i j}$ )denotes whether the students simulated school assignment is single-sex. The simulated single-sex assignment is the excluded instrument. The first stage F-statistics are all above 100. Standard errors are clustered at the simulated school level.

Rule-based instrument using all exogenous variation. To exploit both sources of plausibly exogenous variation simultaneously I use a 2SLS strategy that estimates the effect of attending a single-sex school after controlling for a full set of choice indicator variables (i.e. controlling for the underlying choices that generate variation in school assignments), and smooth functions of the incoming SEA tests scores (i.e. controlling for the underlying test scores that generate variation in school assignments in a smooth manner). I instrument for singlesex school attendance with an indicator variable denoting whether the simulated school is single-sex. Specifically, I estimate the following system of equations by 2SLS where all variables are defined as in (3) where instead of indicator variables for each test score $f\left(S E A_{i}\right)$ is a fifth order polynomial in the student's total SEA score. ${ }^{16}$ The first stage F-statistics are all above 100. Standard errors are clustered at the simulated school level.

$$
\begin{gathered}
\text { single }_{i j}=f_{1}\left(\mathrm{SEA}_{i}\right)+\gamma_{1}\left(\overline{\text { single }} \mid \text { Rule }_{i j}\right)+X_{i} \delta_{1}+\sum_{c=1} I_{i, c} \cdot \theta_{c 1}+\varepsilon_{i, j, 1} \\
Y_{i j}=f_{2}\left(\operatorname{SEA}_{i}\right)+\operatorname{single}_{i j} \sigma+X_{i} \delta_{2}+\sum_{p=1} I_{i, c} \cdot \theta_{c 2}+\varepsilon_{i j 2}
\end{gathered}
$$

\footnotetext{
${ }^{15}$ Each choice group is defined by a distinct preference ordering of schools. All students who list schools A, B, C, D in that order form a group, while students who list schools B, A, C, D are in a different group because the ordering of schools is different. There are 22,649 preference groups with more than one student. Among these groups, the average group has 63 students.

${ }^{16}$ All results are robust to using a third, fourth, fifth, or sixth order polynomial.
}

\subsection{Interpretation of the Local Average Treatment Effects}

The assignment mechanism is such that students with higher school entrance exam scores are more likely to be assigned to more preferred schools. Because single-sex schools are often preferred, attending a single-sex school is associated with attending a preferred school. The coefficients on "single" from (2), (3) and (4) provide a selection free estimate of the effect of attending a preferred single-sex school for those students who apply to single-sex schools. However, these coefficients may not isolate a single-sex schooling effect for two reasons. First, the majority of single-sex schools are also assisted schools (which are more selective, better funded, and have a religious affiliation) so that this comparison of single-sex versus non-singlesex schools is potentially confounded with the effect of attending an assisted school. Second, due to the nature of the assignment mechanism, students are more likely to attend a single-sex school when they gain admission to a preferred school. Given that missing one's top choice school may have an independent effect on student motivation and effort, and could lead to changes in parental inputs (such as extra tutoring) part of the effect of attending a preferred single-sex school may be driven by the psychological or behavioral effects associated with attending a preferred school.

Fortunately, one can exploit variation across cut-offs to remove these confounding factors. Because some cut-offs create exogenous variation to assisted schools but not single-sex schools while others create exogenous variation to single-sex schools but not assisted schools, one can isolate the effect of attending a single-sex school from that of attending an assisted school. Similarly, I can leverage the fact that some cut-offs do not entail being admitted to a singlesex school to isolate the effect of being admitted to a single-sex school from that of scoring above a cut-off for a preferred school. By exploiting variation across cut-offs I can remove the effects of attending a single-sex school from that of the effects of attending an assisted school and the effects of attending a preferred school (irrespective of type).

One can move closer to isolating a single-sex schooling effect by augmenting equation (4) to include an indicator for whether the student attends an assisted school and indicators for whether a student attends their first, second, third, or fourth choice school. To account for selection, I instrument for attending an assisted school with an indicator denoting whether the student was assigned to an assisted school based on the simulation, and I instrument for whether a student attends their first, second, third, or fourth choice school with whether a student was assigned to their first, second, third, or fourth choice school based on the simulation. The interpretation of the coefficient on "single" with these additional covariates would be the effect of attending a preferred single-sex school above and beyond the effect of attending a preferred school, or an assisted school. After presenting estimates of the effect of attending a preferred single-sex school, I will then present results that condition on other attributes to illustrate the underlying mechanisms through which this effect operates and also to move closer to isolating something that can be plausibly interpreted as a single-sex school effect.

\section{Results}

\subsection{Naive estimates of the effect of attending a preferred single-sex school}

To illustrate the importance of addressing student selection in both observed and unobserved dimensions, I first present naive estimates of the effects of attending a single-sex school and then show how the results change as one accounts for selection. Table 3 presents the coefficient on attending a single-sex school on the main academic outcomes analyzed: Taking the CSEC exams (a proxy for not dropping out of school), the number of exams taken, the number of exams 
Table 3

Effect of attending preferred single-sex schools

\begin{tabular}{|c|c|c|c|c|c|c|c|}
\hline & 1 & 2 & 3 & 4 & 5 & 6 & 7 \\
\hline & Peer achievement & Take the CSEC exams & CSEC exams taken & CSEC exams passed & Passed CSEC English & Passed CSEC Math & Earned certificate \\
\hline No controls ( & 8,604 obs.) & & & & & & \\
\hline Single-sex & $\begin{array}{l}1.027 \\
{[0.064]^{* *}}\end{array}$ & $\begin{array}{l}0.488 \\
{[0.049]^{* *}}\end{array}$ & $\begin{array}{l}3.547 \\
{[0.217]^{* *}}\end{array}$ & $\begin{array}{l}3.319 \\
{[0.205]^{* *}}\end{array}$ & $\begin{array}{l}0.496 \\
{[0.023]^{* *}}\end{array}$ & $\begin{array}{l}0.454 \\
{[0.035]^{* *}}\end{array}$ & $\begin{array}{l}0.421 \\
{[0.043]^{* *}}\end{array}$ \\
\hline Fifth order po & nomial in SEA score & ( 218,604 obs.) & & & & & \\
\hline $\begin{array}{l}\text { Single-sex } \\
\text { Fifth order po }\end{array}$ & $\begin{array}{l}0.501 \\
{[0.027]^{* *}} \\
\text { nomial in SEA and }\end{array}$ & $\begin{array}{l}0.375 \\
{[0.031]^{* *}} \\
\text { oice fixed effects }(218,5\end{array}$ & $\begin{array}{l}2.266 \\
{[0.148]^{* *}} \\
4 \text { obs. })\end{array}$ & $\begin{array}{l}1.493 \\
{[0.081]^{* *}}\end{array}$ & $\begin{array}{l}0.224 \\
{[0.015]^{* *}}\end{array}$ & $\begin{array}{l}0.181 \\
{[0.011]^{* *}}\end{array}$ & $\begin{array}{l}0.152 \\
{[0.013]^{* *}}\end{array}$ \\
\hline $\begin{array}{l}\text { Single-sex } \\
\text { 2SLS-DID: ind }\end{array}$ & $\begin{array}{l}0.54 \\
{[0.038]^{* *}} \\
\text { idual SEA test score }\end{array}$ & $\begin{array}{l}0.407 \\
{[0.028]^{* *}} \\
\text { ixed effects and choice }\end{array}$ & $\begin{array}{l}2.471 \\
{[0.139]^{* *}} \\
\text { ed effects }(152,242\end{array}$ & $\begin{array}{l}1.664 \\
{[0.109]^{* *}} \\
\left.\text { s. }{ }^{a}\right)\end{array}$ & $\begin{array}{l}0.244 \\
{[0.018]^{* *}}\end{array}$ & $\begin{array}{l}0.201 \\
{[0.016]^{* *}}\end{array}$ & $\begin{array}{l}0.171 \\
{[0.018]^{* *}}\end{array}$ \\
\hline $\begin{array}{l}\text { Single-sex } \\
\text { 2SLS: fifth orc }\end{array}$ & $\begin{array}{l}0.296 \\
{[0.060]^{* *}} \\
\text { r polynomial in SEA }\end{array}$ & $\begin{array}{l}0.024 \\
{[0.021]} \\
\text { nd preference fixed effe }\end{array}$ & $\begin{array}{l}0.372 \\
{[0.220]+} \\
\text { ts }\left(179,710 \text { obs. }^{\mathrm{a}}\right)\end{array}$ & $\begin{array}{l}0.408 \\
{[0.178]^{*}}\end{array}$ & $\begin{array}{l}0.04 \\
{[0.032]}\end{array}$ & $\begin{array}{l}0.051 \\
{[0.036]}\end{array}$ & $\begin{array}{l}0.058 \\
{[0.025]^{*}}\end{array}$ \\
\hline $\begin{array}{l}\text { Single-sex } \\
\text { 2SLS: fifth orc }\end{array}$ & $\begin{array}{l}0.336 \\
{[0.054]^{* *}} \\
\text { r polynomial in SEA }\end{array}$ & $\begin{array}{l}0.073 \\
{[0.018]^{* *}} \\
\text { choice fixed effects, and }\end{array}$ & $\begin{array}{l}0.736 \\
{[0.163]^{* *}} \\
\text { ssisted school }(179,7\end{array}$ & $\begin{array}{l}0.615 \\
{[0.154]^{* *}} \\
\left.\text { obs. }^{\text {a }}\right)\end{array}$ & $\begin{array}{l}0.054 \\
{[0.020]^{* *}}\end{array}$ & $\begin{array}{l}0.054 \\
{[0.017]^{* *}}\end{array}$ & $\begin{array}{l}0.057 \\
{[0.025]^{*}}\end{array}$ \\
\hline $\begin{array}{l}\text { Single-sex } \\
\text { 2SLS: fifth orc }\end{array}$ & $\begin{array}{l}0.268 \\
{[0.056]^{* *}} \\
\text { r polynomial in SEA }\end{array}$ & $\begin{array}{l}0.065 \\
{[0.020]^{* *}} \\
\text { choice fixed effects, and }\end{array}$ & $\begin{array}{l}0.585 \\
{[0.160]^{* *}} \\
\text { hoice attained fixed }\end{array}$ & $\begin{array}{l}0.442 \\
{[0.158]^{* *}} \\
\text { ects }\left(179,710 \text { obs. }^{\mathrm{a}}\right)\end{array}$ & $\begin{array}{l}0.043 \\
{[0.021]^{*}}\end{array}$ & $\begin{array}{l}0.042 \\
{[0.020]^{*}}\end{array}$ & $\begin{array}{l}0.04 \\
{[0.027]}\end{array}$ \\
\hline $\begin{array}{l}\text { Single-sex } \\
\text { 2SLS: fifth orc }\end{array}$ & $\begin{array}{l}0.157 \\
{[0.053]^{* *}} \\
\text { r polynomial in SEA }\end{array}$ & $\begin{array}{l}-0.082 \\
{[0.044]+} \\
\text { choice fixed effects, and }\end{array}$ & $\begin{array}{l}-0.213 \\
{[0.265]} \\
\text { ssisted, and choice a }\end{array}$ & $\begin{array}{l}0.239 \\
{[0.180]} \\
\text { ined fixed effects (17 }\end{array}$ & $\begin{array}{l}0.018 \\
{[0.023]} \\
\left.710 \text { obs. }^{\mathrm{a}}\right)\end{array}$ & $\begin{array}{l}0.031 \\
{[0.019]}\end{array}$ & $\begin{array}{l}0.026 \\
{[0.025]}\end{array}$ \\
\hline $\begin{array}{l}\text { Single-sex } \\
\text { 2SLS: fifth orc }\end{array}$ & $\begin{array}{l}0.121 \\
{[0.053]^{*}} \\
\text { r polynomial in SEA }\end{array}$ & $\begin{array}{l}-0.059 \\
{[0.042]} \\
\text { preference fixed effects }\end{array}$ & $\begin{array}{l}-0.190 \\
{[0.263]} \\
\text { nd peer quality (17 }\end{array}$ & $\begin{array}{l}0.130 \\
{[0.185]} \\
10 \text { obs.) }\end{array}$ & $\begin{array}{l}0.013 \\
{[0.024]}\end{array}$ & $\begin{array}{l}0.024 \\
{[0.021]}\end{array}$ & $\begin{array}{l}0.014 \\
{[0.027]}\end{array}$ \\
\hline Single-sex & - & $\begin{array}{l}-0.039 \\
{[0.040]}\end{array}$ & $\begin{array}{l}-0.158 \\
{[0.216]}\end{array}$ & $\begin{array}{l}0.009 \\
{[0.145]}\end{array}$ & $\begin{array}{l}-0.008 \\
{[0.022]}\end{array}$ & $\begin{array}{l}-0.001 \\
{[0.018]}\end{array}$ & $\begin{array}{l}-0.011 \\
{[0.020]}\end{array}$ \\
\hline
\end{tabular}

Standard errors in brackets adjusted for clustering at the simulated assigned school level.

The sample sizes for the simulated assignment are smaller than the full sample because students who score very low will have no simulated assignment.

+ Significant at $10 \%$; *Significant at $5 \% ;{ }^{* *}$ Significant at $1 \%$.

a Sample sizes are smaller in the 2SLS models because some observations are dropped due to co-linearity.

passed (a summary statistic for overall academic achievement that is sensitive to the CSEC taking margins and performance on the CSEC), passing the math CSEC exams, passing the English CSEC exams, and earning a certificate (i.e. passing 5 subjects including English and Math. This is the prerequisite to attending tertiary education). Because (Jackson, 2009a,b, 2010, 2011) documents that attending a more selective school is associated with better academic outcomes, I also include mean peer achievement as an outcome to give a sense of how much more selective single-sex schools are to the coed schools they are being compared to.

The naive OLS results indicate that incoming peer achievement is one standard deviation higher, on average, for students who attend single-sex schools than those who do not, and outcomes are much better. Conditional on SEA scores and choice fixed effects (third row) there are still large differences in school selectivity and outcomes such that students who attend single-sex schools are exposed to peers with 0.5 standard deviations higher incoming test scores, are 40 percentage points more likely to take the CSEC exams, take 2.47 more exams, pass 1.66 more exams, are 24 percentage points more likely to pass their CSEC English exam, are 20 percentage points more likely to pass their CSEC math exam, and are 17 percentage points more likely to earn a certificate. These naively estimated effects are large.

\subsubsection{Direct evidence of positive selection into single-sex schools}

To assess the degree of selection into single-sex schools, I compare the incoming achievement of students who express preferences for single-sex schools to those of students who do not. Students who list a single-sex school as their top choice have incoming test scores one standard deviation higher than those who do not. This could be because singlesex schools are more selective and better prepared students put more selective schools on their list. To test for this, I predict incoming test scores as a function of the selectivity of each of the school choices and also whether each of the choices is single-sex. Those who chose a single-sex top, second, third, and fourth choice have test scores 0.06, 0.1, 0.1, and 0.017 standard deviations higher than those who do not (conditional on the other school choices). This is direct evidence of positive selection into single-sex schools that is not merely due to single-sex schools being more selective and highlights the need for exogenous variation in school attendance.

\subsection{Selection free effects of attending a preferred single-sex school}

While my preferred strategy uses both the discontinuity and DID variation simultaneously, I present results for each strategy independently. If both strategies yield similar results, it would suggest that each strategy and the combination of the two yields the true relationship. I show this below.

\subsubsection{Discontinuity variation only}

In Table 4 I present the range of results one obtains using only the discontinuity variation under different choices of bandwidth and different polynomial orders of the SEA scores. The estimates do vary depending on the modeling assumptions made. However, there are general patterns that are reasonably robust. First, attending a singlesex school as a result of scoring above a cut-off for a preferred singlesex school is associated with peer achievement that is between 0.415 and 0.779 standard deviations higher than at a coed school (all 
Table 4

LATE effect of attending a preferred single-sex school using discontinuity variation only.

\begin{tabular}{|c|c|c|c|c|c|c|c|c|c|c|c|c|c|c|c|c|}
\hline \multicolumn{14}{|c|}{ Outcome } & \multirow[b]{2}{*}{$\begin{array}{l}\text { Bandwidth } \\
\text { (SD) }\end{array}$} & \multirow[b]{2}{*}{$\begin{array}{l}\text { Polynomial } \\
\text { of SEA score }\end{array}$} & \multirow[b]{2}{*}{ Obs. } \\
\hline \multicolumn{2}{|c|}{$\begin{array}{l}\text { Peer } \\
\text { achievement }\end{array}$} & \multicolumn{2}{|c|}{ Take CSEC } & \multicolumn{2}{|c|}{ Exams taken } & \multicolumn{2}{|c|}{ Pass English } & \multicolumn{2}{|c|}{ Pass math' } & \multicolumn{2}{|c|}{ Exams passed } & \multicolumn{2}{|c|}{ Certificate } & & & \\
\hline 0.607 & {$[0.259]^{*}$} & -0.16 & [0.202] & -0.26 & [1.353] & -0.042 & [0.211] & 0.036 & [0.171] & 0.486 & [1.221] & 0.022 & [0.211] & 0.5 & 5 & 71941 \\
\hline 0.723 & {$[0.160]^{* *}$} & -0.051 & [0.103] & 0.453 & [0.758] & 0.023 & [0.115] & 0.075 & [0.111] & 1.015 & [0.712] & 0.098 & [0.127] & 0.5 & 4 & 71941 \\
\hline 0.531 & {$[0.141]^{* *}$} & -0.139 & [0.102] & -0.361 & [0.725] & -0.18 & {$[0.126]$} & -0.19 & [0.144] & 0.161 & [0.678] & 0.1 & [0.143] & 0.5 & 3 & 71941 \\
\hline 0.779 & {$[0.097]^{* *}$} & 0.046 & {$[0.052]$} & 0.469 & {$[0.346]$} & -0.147 & {$[0.086]+$} & -0.073 & {$[0.076]$} & 1.012 & {$[0.324]^{* *}$} & 0.102 & [0.084] & 0.5 & 2 & 71941 \\
\hline 0.618 & {$[0.131]^{* *}$} & -0.115 & {$[0.088]$} & 0.018 & {$[0.566]$} & 0.101 & {$[0.093]$} & 0.109 & [0.101] & 0.577 & [0.559] & 0.023 & {$[0.076]$} & 1 & 5 & 96208 \\
\hline 0.415 & {$[0.108]^{* *}$} & -0.116 & {$[0.065]+$} & -0.289 & {$[0.472]$} & -0.11 & {$[0.083]$} & -0.12 & [0.093] & 0.437 & {$[0.437]$} & 0.082 & [0.072] & 1 & 4 & 96208 \\
\hline 0.644 & {$[0.086]^{* *}$} & -0.03 & [0.033] & 0.372 & {$[0.267]$} & -0.142 & {$[0.055]^{*}$} & -0.123 & {$[0.059]^{*}$} & 0.889 & {$[0.310]^{* *}$} & 0.057 & {$[0.074]$} & 1 & 3 & 96208 \\
\hline 0.445 & {$[0.124]^{* *}$} & 0.008 & [0.041] & 0.353 & [0.299] & -0.178 & {$[0.050]^{* *}$} & -0.237 & {$[0.083]^{* *}$} & 0.404 & [0.388] & -0.058 & [0.115] & 1 & 2 & 96208 \\
\hline 0.366 & {$[0.115]^{* *}$} & 0.111 & {$[0.071]$} & -0.401 & [0.533] & -0.156 & {$[0.089]+$} & -0.204 & {$[0.102]^{*}$} & 0.224 & [0.488] & 0.096 & {$[0.043]^{*}$} & 1.5 & 5 & 107203 \\
\hline 0.589 & {$[0.080]^{* *}$} & -0.042 & [0.037] & 0.362 & [0.291] & -0.134 & {$[0.055]^{*}$} & -0.146 & {$[0.064]^{*}$} & 0.902 & {$[0.280]^{* *}$} & 0.084 & {$[0.043]+$} & 1.5 & 4 & 107203 \\
\hline 0.546 & {$[0.144]^{* *}$} & -0.024 & [0.039] & 0.349 & [0.292] & -0.144 & {$[0.075]+$} & -0.125 & [0.084] & 0.691 & {$[0.409]+$} & 0.052 & {$[0.046]$} & 1.5 & 3 & 107203 \\
\hline 0.447 & {$[0.078]^{* *}$} & 0.095 & {$[0.031]^{* *}$} & * 0.692 & {$[0.212]^{* *}$} & -0.251 & {$[0.044]^{* *}$} & -0.28 & {$[0.071]^{* *}$} & 0.126 & [0.295] & -0.007 & [0.040] & 1.5 & 2 & 107203 \\
\hline
\end{tabular}

Standard errors in brackets are adjusted for clustering at cut-off level.

+ Significant at $10 \%$; *Significant at $5 \%$; ${ }^{*}$ Significant at $1 \%$.

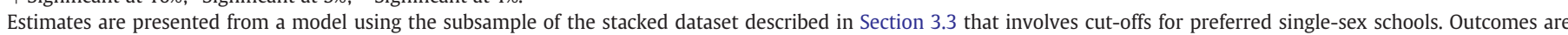

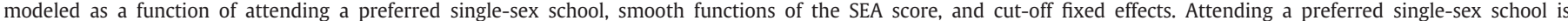
instrumented for with scoring above the cut-off for the preferred single-sex school. The coefficient on "attending a preferred single-sex school" is presented for each outcome.

statistically significant at the $1 \%$ level). While there appears to be little effect on taking the CSEC exams, for the two main overall outcomes the results suggest that students have better outcomes at single-sex schools. Specifically, the point estimates for taking the CSEC range from 0.095 to -0.116 , about half are positive and the other half negative. This suggests a high degree of noise, and is suggestive of no effect on this outcome. However, the point estimates for the number of CSEC exams passed are all positive, ranging between 0.16 and 1.012, and many of the specification are statistically significantly different from zero-suggesting a real positive effect on this outcome. For earning a certificate almost all of the point estimates are positive (but are noisier leading to a range from -0.058 and 0.102 ) and a few positive estimates are statistically significantly different from zero-suggesting an imprecisely estimated but real positive effect. The lower panel of Fig. 3 shows visually the discontinuity evidence for the two main outcomes. Consistent with the regression estimates there appear to be positive effects. While these discontinuity based estimates are imprecise, the range of estimate are centered at about half the size of the naive OLS estimates in Table 3 and the highest discontinuity based point estimates are at least $40 \%$ smaller than the OLS estimate. This provides compelling evidence that the OLS estimates are overstated due to positive selection to single-sex schools. While this is informative about the probable size and sign of the true casual effect, the exact point estimates are sensitive to exactly how one controls for smoothness through the cut-offs. This motivates the use of the DID strategy that yields much more precise estimates.

\subsubsection{Difference in difference variation only}

Row 4 of Table 3 presents the results from the DID models that instrument attending a single-sex school with whether one was assigned to a single-sex school based on the simulation. This model is conditional on indicator variables for each unique test score and each unique combination of school choices orderings. The estimates are consistent with the discontinuity results, but the standard errors are about one quarter the size. Attending a single-sex school is associated with a school with 0.296 standard deviations higher incoming peer achievement (a more selective school). Consistent with the discontinuity model, attending a single-sex school has no effect on CSEC taking, but is associated with passing 0.408 more exams and being 5.8 percentage point more likely to earn a certificate (both significant at the $5 \%$ level). Similar to the discontinuity results, the DID results yield treatment effects about one third the size of the naively estimated treatment effects-again indicative of sizable positive selection bias on unobservables. The only outcome for which there is some disagreement across models is passing math and English. While the discontinuity results suggest that students at single-sex schools fare slightly worse, the DID results suggest no effect. By and large the results are consistent across the two sources of variation. For the main overall outcomes both sets of results indicate that students who attend single-sex schools are no more likely to take the CSEC exams but do pass more exams and are more likely to earn a certificate. Given the similarity of the results across distinct sources of variation, it is reasonable to turn to the preferred model that exploits both sources of variation simultaneously and focus the remaining analysis on this preferred model.

\subsubsection{All exogenous variation}

The rule-based IV strategy exploiting all exogenous variation yields results that are similar to those from the previous models (5th row of Table 3). After accounting for student selection, students who attend single-sex schools are exposed to peers with 0.336 standard deviations higher incoming test scores, are 7.3 percentage points more likely to take the CSEC exams (not drop out of school), take 0.736 more exams, pass 0.615 more exams, are 5.4 percentage points more likely to pass their CSEC English exam, are 5.4 percentage points more likely to pass their CSEC math exam, and are 5.7 percentage points more likely to earn a certificate (the prerequisites to tertiary education). These effects, while positive, are orders of magnitudes smaller than the OLS estimates (and on the same order of magnitude as the discontinuity-only and DID-only results), underscoring the importance of exploiting exogenous variation when analyzing the effects of single-sex schools. In sum, the results show that there are real positive effect associated with attending a single-sex school that cannot be attributed to student selection. In Section 4.3 I investigate whether this real positive effect reflects a single-sex school effect or is due to other factors associated with attending single-sex schools.

\subsubsection{Specification checks and falsification tests}

To show that my identification strategy is valid, I first present evidence that the simulated cut-offs are exogenous. The first test of this is to see if there is less density right below a cut-off and more density right above the cut-off than would be expected by random chance. Such a pattern would be consistent with gaming of the cut-offs. Using the stacked dataset (as described in Section 3.3) I test this. Appendix Figure A2 shows the density of incoming scores and the vertical line is the cut-off. There is little evidence of such a pattern. Following McCrary (2008), I test for discontinuity in the density of the total score at the simulated cut-off while controlling for a fifth order polynomial in the relative score. Where the dependent variable 


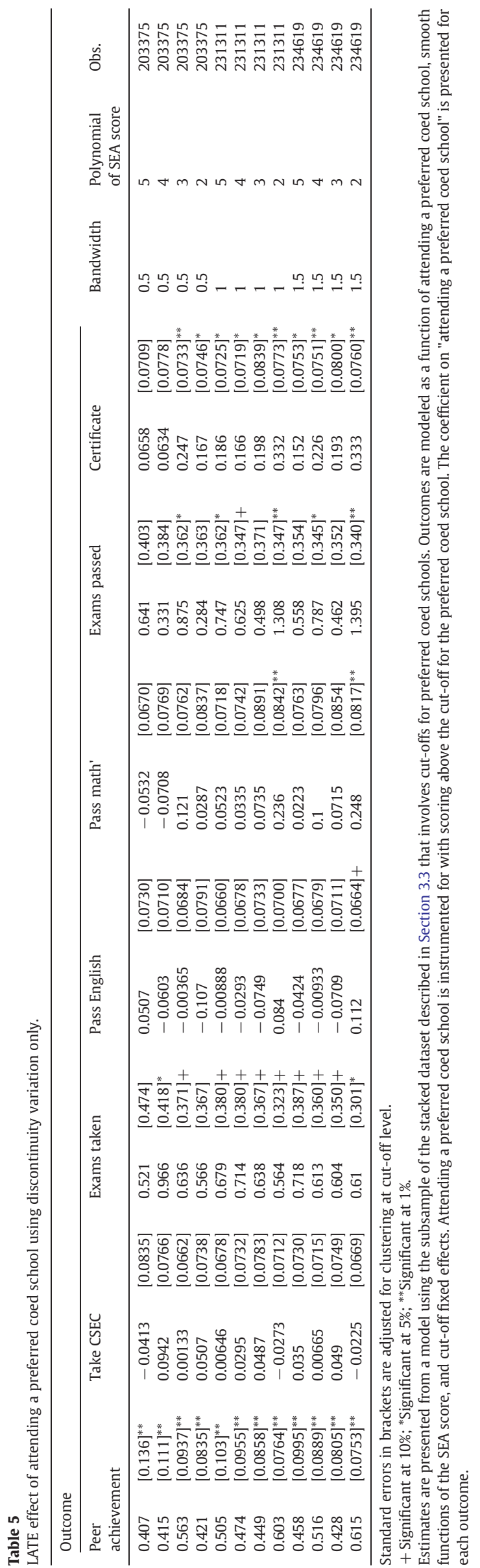

is the empirical density, the coefficient on an indicator variable denoting "above cut-off" is a statistically and economically insignificant -0.003 ( $p$-value $=0.2$ )-suggesting no gaming.

If the cut-offs are exogenous, preferences should be balanced above and below the cut-off and there should be no difference in the selectivity of school choices for those assigned to single-sex schools conditional on school choices and test scores. As a second check on the discontinuity variation, I regress mean peer test scores at the first choice school on a fifth order polynomial in the relative score and the "above cut-off" indicator (Appendix Table A1). This yields a coefficient on "above cut-off" of -0.008 (se =0.019). The same exercise with the second, third, and fourth choice schools yield similarly small and statistically insignificant coefficients (none yield $p$-values below 0.3 ). There is also no evidence of shifts in other observables (religion and primary school district) associated with the cut-offs.

While one cannot estimate models with the full interaction between all test scores and all choices in the DID model (because this is the level of the variation), as a check on the DID variation, one can estimate models with interactions between coarse measures of test scores and coarse measures of choices. Because an average student who lists a single-sex school may differ from an average student that does not, I include group indicator variables defined by the unique combination of five indicators for the student's test score quintile, and four indicators for whether the first, second, third, and fourth choice school is single-sex. These group indicators control for coarse interactions between test scores and school choices such that the comparisons are made among students with similar test scores and similar choices within which the assumption of additivity is likely to hold. Results from this specification (not shown) are almost identical to those from the models without these indicator variable, suggesting that the DID identifying assumption of additive separability is valid.

Finally, I test the preferred model by seeing if having a simulated single-sex assignment is correlated with having preferences for more selective schools or any observable characteristic conditional on smooth functions of test scores and choice indicator variables (Appendix Table A1). All 23 covariates tested yield small point estimates, and none yield $p$-values on "simulated same sex" smaller than 0.05. All these tests suggest that the empirical strategies employed are likely valid.

\subsection{Isolating the single-sex schooling effect}

The effect of attending a preferred single-sex school may not isolate a single-sex schooling effect because it may be confounded with the effect of attending an assisted school and the effect of attending a preferred school (of any type). I present results that account for these sources of confounding below.

\subsubsection{Are the results driven by an assisted school effect?}

To remove the effect of attending a preferred assisted school from that of attending a preferred single-sex school, I instrument for and include attending an assisted school as a covariate (Row 6 of Table 3). For all outcomes, conditioning on school type reduces the estimated effects by approximately $20 \%$. This indicates that while a modest portion of the estimated benefits to attending a single-sex school may have to do with the fact that such schools are assisted schools, this does not drive the results.

4.3.2. Are the results driven by benefits to gaining admission to a preferred school of any kind?

To isolate the effect of scoring above the cut-off for a preferred school from that of attending a single-sex school, I instrument for and include attending one's first, second, third, and fourth choice school as covariates (Row 7 of Table 2). Conditional on the choice attained, students who attend a preferred single-sex school end up with peers that are $15 \%$ of a standard deviation better than those who attend a coed school. Despite attending more selective schools such students experience no statistically 


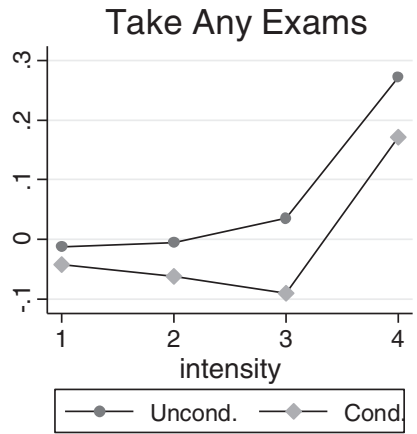

Pass English
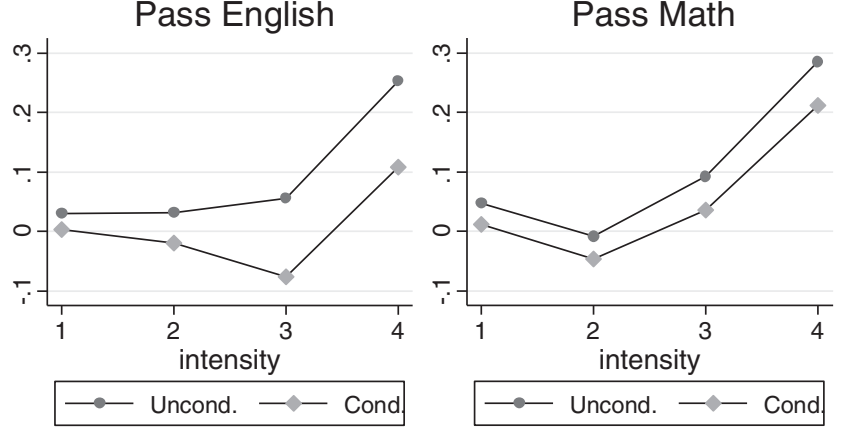

Exams Taken

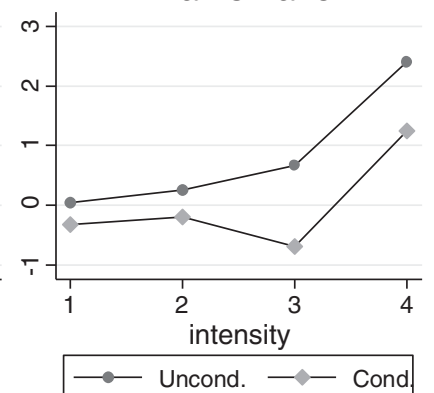

Pass Math

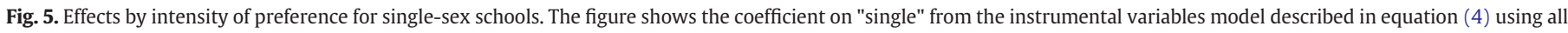

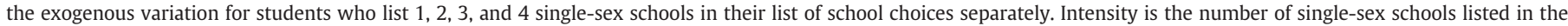

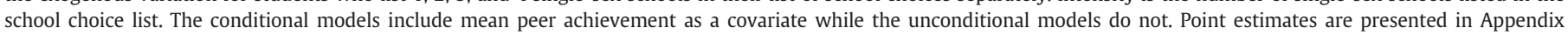
Table A2.

significant benefits to attending a single-sex school. The point estimates are much smaller than the unconditional causal estimates suggesting that the benefits to attending a single-sex school per se, if any, are small.

I also I estimate discontinuity models similar to (2) using cut-offs where the preferred school is a coed school, where attending a preferred school is the endogenous treatment, and scoring above the cut-off for a preferred school is the excluded instrument. The results presented in Table 5 for various bandwidths and polynomial orders of the running SEA variable reveal that attending a preferred coed school leads to improvements that are very similar to (and often larger than) the effects of attending a preferred single-sex school-suggesting that benefits associated with scoring above a cut-off for a preferred school can explain all the benefits to attending a preferred single-sex school.

\subsubsection{Do students perform better at single-sex schools than equally selective coed schools?}

The results thus far indicate that despite being more selective, conditional on school type and being admitted to a preferred school there is little to no benefit to attending a single-sex-school. Even though school selectivity may be endogenous to whether the school is single-sex, readers may find it instructive to see if single-sex schools have better outcomes compared to equally selective coed schools. ${ }^{17}$ The bottom panel of Table 3 presents 2SLS results that condition on school selectivity. Because peer quality (average incoming SEA scores at the school) is a characteristic of the school, and students select to schools, I instrument for peer quality at the school attended

\footnotetext{
${ }^{17}$ Conditioning on school selectivity does not credibly isolate the single-sex-school effect may yield a lower bound estimate because (a) single-sex schools being better may be reflected in their being more selective so that conditioning on selectivity would be "over-controlling" and, (b) if school selectivity is a good measure of school quality and if single-sex schools do improve outcomes then a single-sex school must have worse inputs than an equally selective coed school so that the "single-sex" will be correlated with worse inputs and be downward biased. Because school selectivity and school value-added track very closely together in Trinidad and Tobago (Jackson, 2009a,b, 2010, 2011) models that condition on school selectivity likely yield a lower bound.
}

with the peer quality at the simulated assigned school. These conditional effects yield results that are all close to zero, and not statistically significant. This implies that attending a single-sex school provides no benefit over attending an equally selective coed school.

The results suggest that single-sex schooling per se is not associated with better outcomes on average. If there were real effects of attending single-sex schools due to the schools being single-sex, there should be some benefit to attending a preferred single-sex school above and beyond the effect attending any preferred school per sebut this is not the case. It is therefore not surprising that attending a single-sex school provides no benefit over attending an equally selective coed school on average.

\subsection{Response heterogeneity by preferences for single-sex schools}

If there is response heterogeneity and individuals rationally select to schools based on their private benefits of attending a school, then the treatment effect for students with strong preferences for singlesex schools may be much larger those of students with weak preferences for single-sex schools. The fact that I observe student choices allows me to investigate this. I infer the intensity of a student's preferences for single-sex schools based on the number of singlesex schools they put in their list. In the population, $40 \%$ of students list zero single-sex schools in their choices, $27 \%$ list one, $17 \%$ list two, $10 \%$ list three, and $4 \%$ list four single-sex schools. As expected, those who actually attend single-sex schools have stronger preferences for single-sex schools than the average student. Among students who are both assigned to and who attended single-sex schools, $9 \%$ list one, $31 \%$ list two, $38 \%$ list 3, and $20 \%$ list four singlesex schools. Because only $14 \%$ of all students have strong preferences for single-sex schools (list 3 of 4 schools) while almost $60 \%$ of those who actually attend single-sex schools have strong preferences for single-sex schools, the treatment effect for the marginal student, may be very different from that of the average treated student, which may be very different from that of the average student in the population. 
Take CSEC

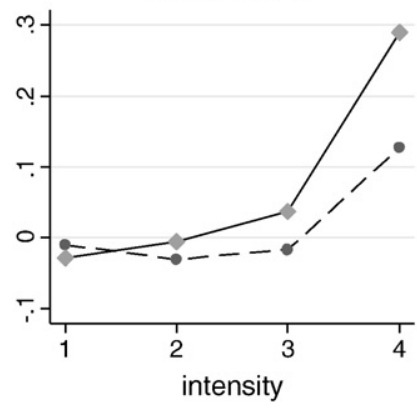

Pass English

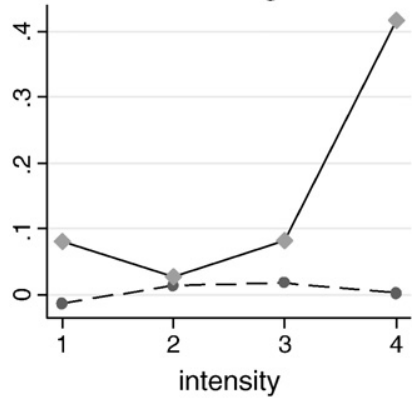

Exams Taken

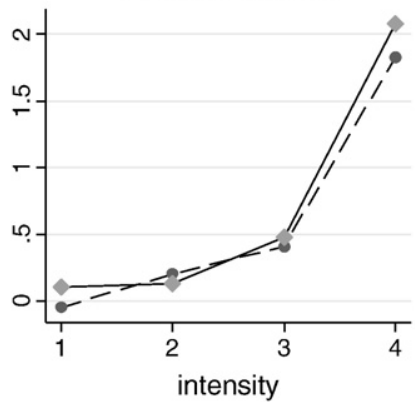

Pass Math

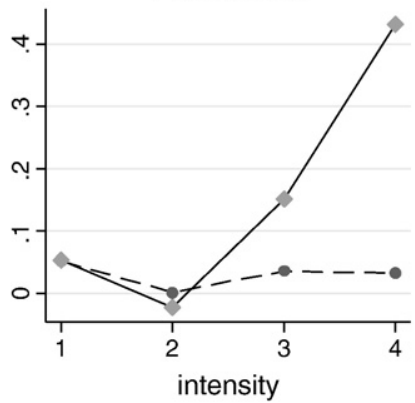

Exams Passed

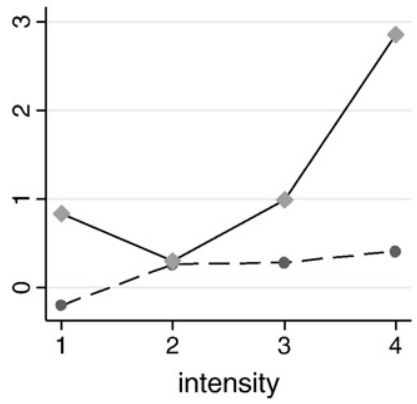

Certificate

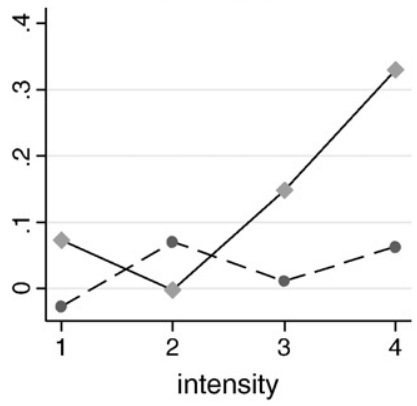

Females are solid lines and Males are dashed lines.

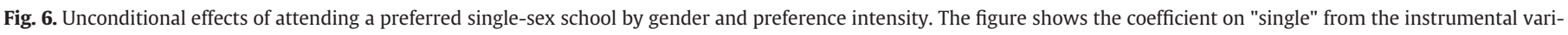

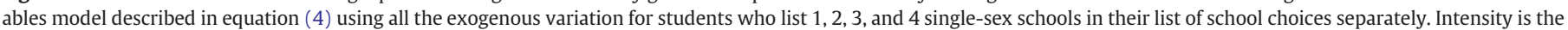

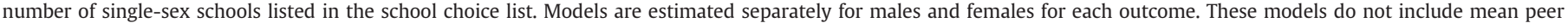
achievement as a covariate. Point estimates are presented in Appendix Tables A3 and A4.

To test for response heterogeneity by preference for single-sex schools, I estimate both the preferred 2SLS models (that do not condition on school type, choice attended, or selectivity) and the preferred 2SLS models conditional on peer selectivity for students who list 1,2, 3, and 4 single-sex schools in their choices separately. I cannot estimate causal effects for those who do not list any single-sex school choices because they will not be assigned to a single-sex school based on the simulated assignment algorithm. Because I aim to document non-zero effects for certain sub-populations, I estimate the more conservative 2SLS model that conditions on incoming peer achievement and yields estimates that are closer to zero than those that condition on school type and attending a preferred school. ${ }^{18}$ I present unconditional and conditional effects graphically in Fig. 5 (estimates are in Appendix Table A2).

Across all outcomes there is a pattern of unconditional effects close to zero for students who only list one or two single-sex schools, modest positive effects for students who list three single-sex schools, and large positive effects for students who list four single-sex schools. For all outcomes, one cannot reject the null hypothesis that the unconditional effect of single-sex schools is zero for students with one or two single-sex school choices. Moreover, the unconditional (likely an upper bound) effects are sufficiently small that one can rule out meaningful single-sex school effects for $85 \%$ of the student population.

For the $14 \%$ of students with strong preferences for single-sex schools the unconditional effects are large enough, and the estimates statistically significant enough, that one cannot rule out null effects for these students. The conservative results that condition on school selectivity show that this group of students do benefit from attending single-sex schools. Specifically, the point estimates for those with three and four choices are large and very similar to the unconditional estimates. A Housman test fails to reject equality of the conditional

\footnotetext{
${ }^{18}$ However, to assuage worries that this modeling assumption drives the results have verified that the pattern of results are very similar in models that condition on school type and choice rank attended.
}

and unconditional estimates for these students, so that one should trust the unconditional estimates which are large and statistically significant. This conditional result provides a justification for positive selection into single-sex schools conditional on school selectivity (at least for those with strong preferences for single-sex schools).

Readers may wonder whether a small subset of the single-sex schools drive the effect for high-preference students. To test for this, I compute the fraction of students assigned to each school in the high-preference group ( 4 choices) and then reweight the sample for the other groups to reflect the contribution of each of the assigned schools that exists in the high-preference group. If the results were driven by those with 4 choices attending better single-sex schools than those with 1 or 2 , then the reweighted regressions for the low preference groups would yield similar estimates to that of the 4 choice sample. In fact, the weighted results (not shown) exacerbate the differences across groups-indicating that differential school quality does not explain the response heterogeneity, that students respond differently to different types of schools, and students select into schools that best match their specific needs. In sum, the results show that only $14 \%$ of the population benefit from attending single-sex schools such that while providing a single-sex schooling option should increase academic outcomes for these students, turning all schools into single-sex schools will not improve outcomes on average.

\subsection{Effects by gender}

To assess the extent to which single-sex schools benefit girls and boys differentially, I estimate the unconditional effects and conditional effects by the number of single-sex school choices for males and females separately (appendix Tables A3 and A4). Fig. 6 shows the unconditional effect for each outcome separately for females and males. For all outcomes, the unconditional effect is larger for females than for males, and almost all of the positive effects are driven by females. Specifically, for the number of exams passed and earning a certificate one can reject the null hypothesis that the unconditional 
treatment effect is zero for females with strong preferences for singlesex schools (at the 1\% level), while one cannot reject the null hypothesis that the unconditional effect for males is zero for any preference intensity group (at the $20 \%$ level). Given that these unconditional estimates are likely upper-bound estimates, the lack of either economic or statistical significance for males is telling. The conditional estimates also suggest real positive effects for females. That is, females with four single-sex school choices pass 3.2 more exams and are 39 percentage points more likely to earn a certificate at single-sex schools than at a similarly selective coed school. While these effects are not very precisely estimated, they are larger than the unconditional estimates which are both statistically significant at the 5\% levelsuggesting that there is a real positive effect for females with strong preferences for single-sex schools. These results are consistent with the commonly held belief that single-sex schools improve the outcomes of some girls but have little effect on the outcomes of boys.

\subsection{Effect of single-sex schooling on course selection}

To assess whether attending a single-sex school has an effect on the course selections of students, I present the unconditional and conditional 2SLS estimates on the number of female courses, and science classes taken by preference strength for males and females separately in Fig. 7. Both the unconditional and the conditional estimates yield no statistically or economically significant effects on the course taking of boys. In contrast, both models suggest that attending a single-sex school increases the number of female dominated subjects taken for females. As with the other outcomes, this effect is increasing in the number of single-sex schools the students lists and the effects are large and statistically significant for females. Also, both the unconditional and the conditional results suggest that attending a single-sex school decreases the number of sciences taken for all females except those with four choices (where the effect is not distinguishable from zero). Note that all schools are to offer the same courses so that any differences in course taking reflect differences in demand rather difference in supply across schools. The results run counter to the argument that single-sex schooling reduces traditional gender roles and that girls take more math and science courses at singlesex schools.

\section{Conclusions}

Single-sex schooling is prevalent in many nations and is becoming increasingly popular in the United States. Despite the important policy implications associated with single-sex schools and psychological, sociological, and biological reasons why both boys and girls might benefit from attending single-sex schools, there has been no clean credible evidence that single-sex schooling actually improves student outcomes. Owing to the unique setup of the education system and the data in Trinidad and Tobago, I am able to deal with the identification challenges that plagued the extant literature.

I find that a failure to account for student selection can lead to large spurious benefits to attending single-sex schools. Once student selection is accounted for, attending a single-sex school is associated with modest improvements. An investigation into the mechanisms however, reveals that this positive effect is not due to the school being single-sex per se, but is due to benefits associated with being admitted to a preferred school (irrespective of the type of school) and to a smaller extent single-sex schools being government assisted schools as opposed to traditional government schools. These small overall effects mask considerable heterogeneity, such that girls with strong preferences for single-sex schools enjoy large benefits, while for most students there is no effect on achievement. Looking to course selection, there is weak evidence that females may take fewer science courses at single-sex schools.

\section{Female Subjects Taken: By Gender}
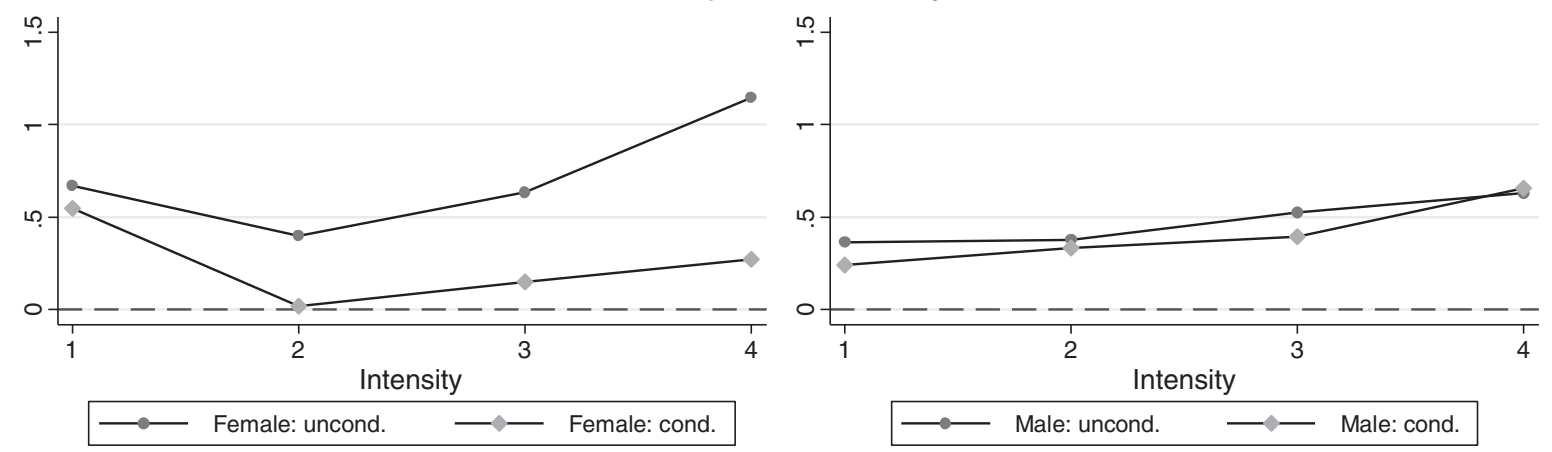

Sciences Taken: By Gender
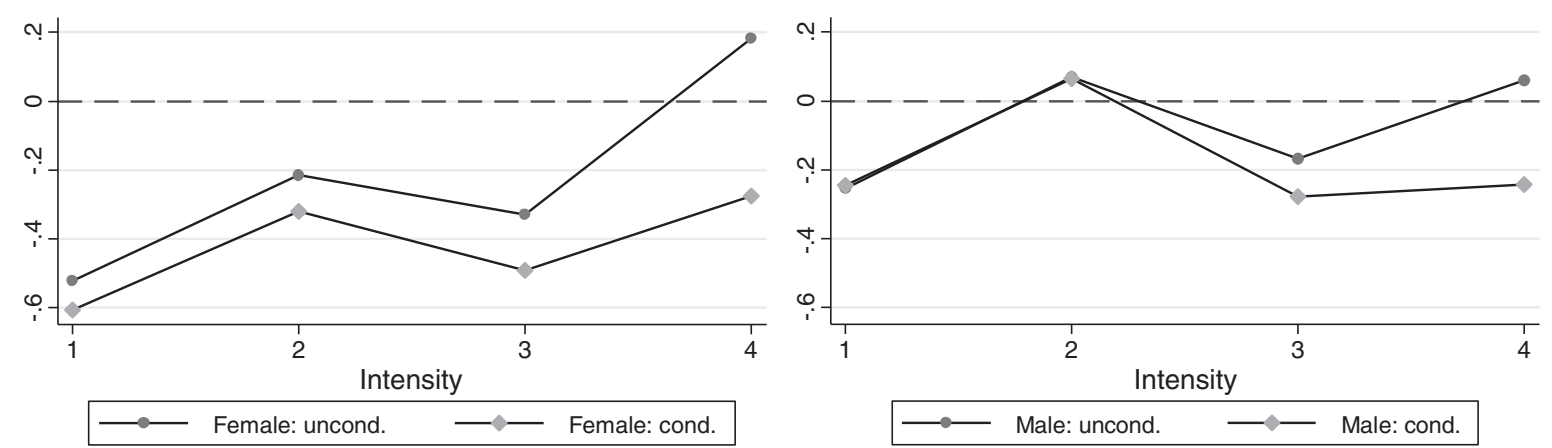

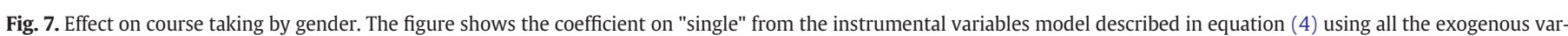

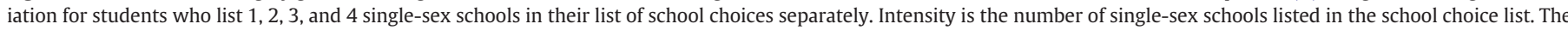

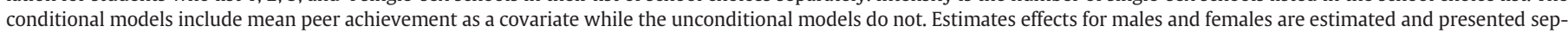
arately for each outcome. 
From a policy perspective, the results suggest that while a school choice policy that included single-sex schools as an option for students is likely to improve outcomes for those few who will likely select to single-sex schools, a broad expansion of single-sex schools may have little benefit. Also, there is little evidence that single-sex schools lead to a more efficient allocation of talent to subject areas or would be an effective policy tool for increasing female representation in math, and science fields.

While the results suggest that single-sex schools may not be effective for most students, single-sex school attendance could have effects on important social outcomes not measured in this study. Also, because this study looks at secondary schools, they do not speak to the possible benefits of single-sex elementary schools or single-sex colleges. However, given that I find evidence of substantial positive self-selection to single-sex schools, and I find that the benefits are much larger for the typical student who attends a single-sex school than the average student, the results suggest that policy-makers should be skeptical in their reading of studies on single-sex schools using observational data, and that studies based on credible research designs but only identify the effects among school applicants should be interpreted with caution. It is evident that we need more studies using credible empirical designs to deepen our understanding of single-sex schools. This study represents a useful first step in this direction.

\section{Appendix A. Supplementary data}

Supplementary data to this article can be found online at doi:10. 1016/j.jpubeco.2011.09.002.

\section{References}

Beyer, Sylvia, Bowden, Edward M., 1997. "Gender differences in self-perceptions: convergent evidence from three measures of accuracy and bias.". Personality and Social Psychology Bulletin XXIII, 157-172.

Campbell Donald, T., 1969. "Reforms and experiments.". The American Psychologist 24, 409-429.

Coleman, J., 1961. The adolescent society. Free Press, New York.

Ding, Weili, Lehrer, Steven F., 2007. Do peers affect student achievement in China's secondary schools? The Review of Economics and Statistics 89 (2), 300-312.

Eagly, A.H., 1978. "Sex differences in influenceability.". Psychological Bulletin 85, 86-116.

Harker, R., 2000. Achievement, gender and the single-sex/coed debate. British Journal of Sociology of Education 21 (2), 203-218.

Higgins, E.T., 1991. "Development of self-regulatory and self-evaluative processes: costs, benefits, and trade-offs.". Self processes and development, edited by Gunnar and Sroufe. University of Minnesota Press, Minneapolis, pp. 125-165.

Hoxby, Caroline, 2000. "Peer effects in the classroom: learning from gender and race variation.". National Bureau of Economic Research Working Paper, p. 7867.
Jackson, C. Kirabo, 2009a. Social and Economic Networks. Princeton University Press, Princeton.

Jackson, Matthew O., 2009. Student demographics, teacher sorting, and teacher quality: evidence from the end of school desegregation. Journal of Labor Economics 27 (2), 213-256.

Jackson, C. Kirabo, 2009b. "Ability-grouping and academic inequality: evidence from rule-based student assignments.". National Bureau of Economic Research Working Paper.

Jackson, C. Kirabo, 2010. "Do students benefit from attending better schools?: evidence from rule-based student assignments in Trinidad and Tobago.". The Economic Journal.

Jackson C. Kirabo, 2011. "Peer Quality or Input Quality? Evidence from Trinidad and Tobago". NBER working paper Number 16598.

James, Abigail Norfleet, Richards, Herbert, 2003. "Escaping stereotypes: educational attitudes of male alumni of single-sex and coed schools.". Psychology of Men and Masculinity 4, 136-148.

Jimenez, E., Lockheed, M.E., 1989. Enhancing girls' learning through single-sex education: evidence and a policy conundrum. Educational Evaluation and Policy Analysis 11 (2), 117-142.

Killgore, William D., Yurgelun-Todd, Deboroah A., 2004. Sex related developmental differences in the lateralized activation of the prefrontal cortex and the amygdala during the perception of facial affect. Perceptual and Motor Skills 99, 371-391.

Lavy, Victor, Schlosser, Analía, 2009. "Mechanisms and impacts of gender peer effects at school.". working paper.

Lee, V.E., Bryk, A.S., 1986. Effects of single-sex schools on student achievement and attitudes. Journal of Educational Psychology 78 (5), 381-395.

Lenroot, Rhoshel K., et al., 2007. "Sexual dimorphism of brain developmental trajectories during childhood and adolescence.". NeuroImage 36, 1065-1073.

LePore, P.C., Warren, J.R., 1997. A comparison of single-sex and coed catholic secondary schooling: evidence from the national educational longitudinal study of 1988 . American Educational Research Journal 34 (3), 485-511.

Maccoby, E.E., Jacklin, C.N., 1974. The psychology of sex differences. Stanford University Press, Stanford

Malacova, E., 2007. "Effect of single-sex education on progress in GCSE.". : Oxford Review of Education, 33. 2.

Marsh, H.W., 1989. Effects of attending single-sex and coed high schools on achievement, attitudes, behaviors, and sex differences. Journal of Educational Psychology 81 (1), 70-85.

McCrary, Justin, 2008. Manipulation of the Running Variable in the Regression Discontinuity Design: A density test. Journal of Econometrics 142 (2), 698-714.

McLane, Katherine, Chad, Colby, Samara, Yudof, Jim, Bradshaw, 2006. "Secretary spellings announces more choices in single sex education amended regulations give communities more flexibility to offer single sex schools and classes". US department of Education Press. Release October 24.

Pomerantz, Eva, Altermatt, Ellen, Saxon, Jill, 2002. Making the grade but feeling distressed: gender differences in academic performance and internal distress. Journal of Educational Psychology 94 (2), 396-404.

Riordian, C., 1990. Girls and Boys in School: Together or Separate? Teachers College Press, New York.

Spielhofer, Thomas, Benton, Tom, Schagen, Sandie, 2004. A study of the effects of school size and single-sex education in English schools. Research Papers in Education 19 (2), 133-159.

Trickett, Edison, Trickett, Penelope, 1982. The independent school experience: aspects of the normative environment of single-sex and coed secondary schools. Journal of Educational Psychology 73 (3), 374-381. 